OPEN ACCESS

Edited by:

Masliza Mahmod,

University of Oxford, United Kingdom

Reviewed by: Jian Yang,

The First People's Hospital of Yichang,

China

Juan Carlos Sepúlveda-Arias, Technological University of Pereira,

Colombia

*Correspondence:

Nadiah Sulaiman

nadiahsulaiman@ukm.edu.my

Specialty section:

This article was submitted to

Ethnopharmacology,

a section of the journal

Frontiers in Pharmacology

Received: 02 February 2021

Accepted: 29 April 2021

Published: 21 May 2021

Citation:

Vijakumaran U, Yazid MD, Hj Idrus RB, Abdul Rahman MR and Sulaiman N (2021) Molecular Action of Hydroxytyrosol in Attenuation of Intimal

Hyperplasia: A Scoping Review.

Front. Pharmacol. 12:663266.

doi: 10.3389/fphar.2021.663266

\section{Molecular Action of Hydroxytyrosol in Attenuation of Intimal Hyperplasia: A Scoping Review}

\author{
Ubashini Vijakumaran ${ }^{1}$, Muhammad Dain Yazid ${ }^{1}$, Ruszymah Bt Hj Idrus ${ }^{1,2}$, \\ Mohd Ramzisham Abdul Rahman ${ }^{3}$ and Nadiah Sulaiman ${ }^{1 *}$
}

${ }^{1}$ Centre for Tissue Engineering and Regenerative Medicine, Universiti Kebangsaan Malaysia Medical Centre, Kuala Lumpur, Malaysia, ${ }^{2}$ Department of Physiology, Faculty of Medicine, Universiti Kebangsaan Malaysia Medical Centre, Kuala Lumpur, Malaysia, ${ }^{3}$ Department of Surgery, Faculty of Medicine, Universiti Kebangsaan Malaysia Medical Centre, Kuala Lumpur, Malaysia

Objective: Hydroxytyrosol $(\mathrm{HT})$, a polyphenol of olive plant is well known for its antioxidant, anti-inflammatory and anti-atherogenic properties. The aim of this systematic search is to highlight the scientific evidence evaluating molecular efficiency of HT in halting the progression of intimal hyperplasia $(\mathrm{IH})$, which is a clinical condition arises from endothelial inflammation.

Methods: A systematic search was performed through PubMed, Web of Science and Scopus, based on pre-set keywords which are Hydroxytyrosol OR 3,4dihydroxyphenylethanol, AND Intimal hyperplasia OR Neointimal hyperplasia OR Endothelial OR Smooth muscles. Eighteen in vitro and three in vitro and in vivo studies were selected based on a pre-set inclusion and exclusion criteria.

Results: Based on evidence gathered, HT was found to upregulate PI3K/AKT/mTOR pathways and supresses inflammatory factors and mediators such as IL-1 $\beta, I L-6$, E-selectin, P-selectin, VCAM-1, and ICAM-1 in endothelial vascularization and functioning. Two studies revealed HT disrupted vascular smooth muscle cells (SMC) cell cycle by dephosphorylating ERK1/2 and AKT pathways. Therefore, HT was proven to promote endothelization and inhibit vascular SMCs migration thus hampering $\mathbb{H}$ development. However, none of these studies described the effect of HT collectively in both vascular endothelial cells (EC) and SMCs in $\mathrm{IH}$ ex vivo model.

Conclusions: Evidence from this concise review provides an insight on HT regulation of molecular pathways in reendothelization and inhibition of VSMCs migration. Henceforth, we propose effect of $\mathrm{HT}$ on $\mathrm{H}$ prevention could be further elucidated through in vivo and ex vivo model.

Keywords: hydroxytyrosol, intimal hyperplasia, neointimal hyperplasia, smooth muscle cell, endothelial cell 


\section{INTRODUCTION}

\section{Intimal Hyperplasia and Current Treatments}

Annually, millions of coronary artery bypass surgery (CABG) and percutaneous coronary interventions (PCI) are performed to treat ischemic heart disease. However, the development of intimal hyperplasia $(\mathrm{IH})$ limits the long-term efficacy of these cardiovascular interventions (Mylonaki et al., 2018). Intimal hyperplasia is defined by thickening of the intimal layer of a blood vessel as a response to endothelial injury, which occurs during or post-surgical procedures such as PCI or CABG (Gellman et al., 1991). Endothelial injury triggers inflammation and platelet activation which subsequently stimulates the proliferation and migration of smooth muscle cells (SMCs) from media toward the intimal layer. SMCs migration is highly assisted by the secretion of inflammatory factors and mediators and degradation of multiple extracellular matrix (ECM) components in the media and adventitia (Jennette and Stone, 2014). This cascade reaction eventually leads to atherosclerosis where the blood vessel narrowed, and surrounding tissues falls into ischemic condition. Unfortunately, the formation of $\mathrm{IH}$ decreases the patency of bypass grafted veins to $40 \%$ after 10-20 years following surgery (de Vries and Quax, 2018).

Despite cutting edge therapies, IH remains as the main risk after CABG with no known remedy to reduce or relinquish the ever-progressing condition. Antithrombotic drugs are the classic approach to prevent IH (Hillis et al., 2012; Anderson et al., 2013). However, prolonged dual-antiplatelet therapy post angioplasty and stent implantation increases the risk of internal bleeding (Costa et al., 2015; Urban et al., 2019). First-generation drugeluting stent (DES) incorporated with antiproliferative drugs like Sirolimus and Paclitaxel, were used to replace bare-metal stent (BMS) (Stone et al., 2007) has significantly reduced the recurrence of occlusion (Stettler et al., 2007; Jennette and Stone, 2014). Unfortunately, increased late stent thrombosis were also reported (Stone et al., 2007). DES efficiently prevent the migration of SMCs by disrupting SMCs cell cycle but with the price of delayed re-endothelization due to the antiproliferative effect of the drug on endothelial cells (ECs) (Camenzind et al., 2007; Joner et al., 2008).

Moving forward, bioresorbable stent (BRS) technology were introduced where the stents could be completely resolved after six months of implantation (Luo et al., 2014) leaving zero traces of stents material. This ultimately reduces future complications like stent migration, endothelial dysfunction, and restenosis (Gonzalo and Macaya, 2012). Unfortunately, BRS mechanical properties i.e. strut thickness, causes vessel injury and subsequently leads to platelet recruitment and thrombosis (Lee and Hernandez, 2018). In addition to that, concern about the degradation and disintegration of BRS into its by-products and its elimination in the coronary artery adds more challenges to the use of BRS. Large and small randomized trials of BRS implantation, unveiled thrombosis and intimal proliferation at one year follow up (Jinnouchi et al., 2019). Moreover, Optical Coherence Tomography (OCT) of an implanted Bioresorbable
Novolimus-Eluting Coronary in patient revealed that the implanted scaffold collapsed and increased of neointimal proliferation in the artery (Alfonso and García-Guimaraes, 2017); Braun et al., 2016). Absorb Bioresorbable Vascular Scaffold (BVS; Abbott Vascular) is the first FDA-approved BRS, but it failed to ensure sustained success with increased late thrombosis events reported that leads to its withdrawal from the market due to low demand (Jinnouchi et al., 2019). BRSs are being redeveloped by taking into consideration several issues that include the strut thickness, degradation efficiency, scaffold thrombosis, and currently waiting to be evaluated in largescale clinical trials (Regazzoli et al., 2017).

\section{Plant-Based Approach for IH}

Various herbal plant-based components were studied for their cardiovascular protection effect (Barnard et al., 2019; Kim et al., 2019; Tuso et al., 2015). Xu et al. compiled a list of natural plant derived compounds such as flavonoids, polyphenols, alkaloids, and terpenes that were found to efficiently suppress VSMCs migration and proliferation (Xu et al., 2018). They further elucidated the involvement of typical cell regulatory and inflammatory pathways including MAPKs, PI3K/Akt, JAKSTAT, FAK, and NF- $\mathrm{KB}$ in VSMCs migration. However, they focused solely on activity of plant base compounds on VSMCs and not collectively with endothelial cells which is also an essential cell in pathophysiology of IH.

Polyphenol such as resveratrol is the most studied compound in IH prevention. Balloon catheters coated with resveratrol effectively deliver resveratrol to the targeted site and successfully reduce IH development in rabbit models (Tolva et al., 2016). In addition to that, a series of in vivo animal studies showed that resveratrol promoted re-endothelization and vascular healing post-surgical anastomosis (Yurdagul et al., 2014; Karaarslan et al., 2015; Kamann et al., 2019). Kamann et al. reported that resveratrol increases ECs proliferation via activating extracellular signal-regulated kinase (ERK) and estrogen receptor-dependent pathway under laminar shear stress (Yurdagul et al., 2014). Interestingly, curcumin also ameliorated IH by increasing endothelial angiogenesis and proliferation in an artery injured rat (Chen et al., 2015).

Alternatively, quercetin (Khandelwal et al., 2012) and salvianolic acid A (SAA) (Sun et al., 2012) were also found to inhibit proliferation of VSMCs too. Intriguingly, a green tea polyphenol, epigallocatechin-3-gallate (EGCg), suppressed neointimal hyperplasia $(\mathrm{NIH})$ in rabbit model by inhibiting the proliferation of VSMCs via inactivation of MAPKs pathway In a recent study, Wei delivered mesoporous silica nanoparticles encapsulated honokiol (HNK), a small molecule polyphenol after balloon injury and HNK greatly suppressed intimal thickening by reducing phosphorylation of Smad3 (Wei et al., 2020).

\section{Hydroxytyrosol as an Innovative Approach}

Olive oil is the primary source of fat and polyphenols in Mediterranean Diet (MD) (Widmer et al., 2015). In 2013, the United Nations Educational, Scientific and Cultural Organization 


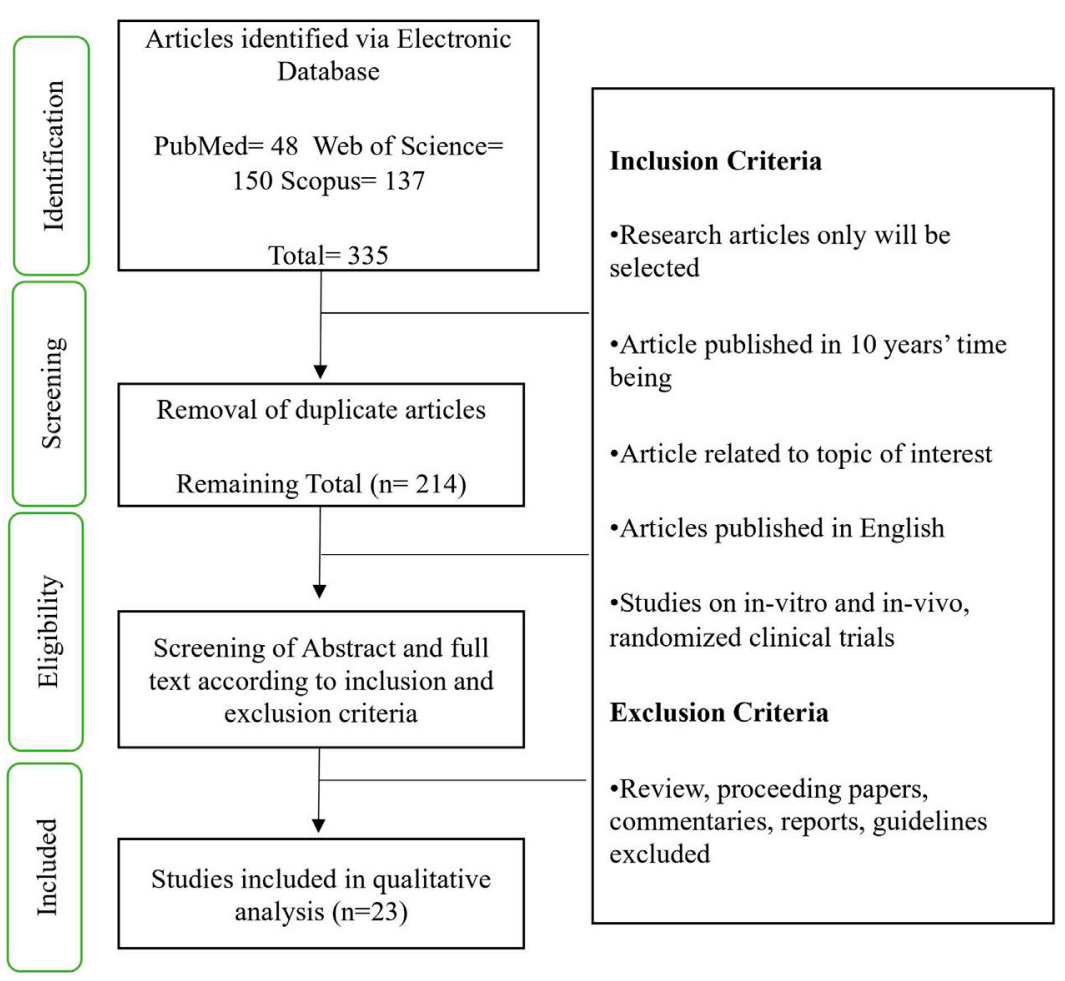

FIGURE 1 | Flow chart represent selection and screening process based on PRISMA.

(UNESCO) include $\mathrm{MD}$ in the "Representative List of the Intangible Cultural Heritage of Humanity". MD was also classified in the 2015-2020 Dietary Guidelines for Americans as a healthy diet (Romagnolo and Selmin, 2017). Phytochemicals from olive plant showed positive correlation with the reduction of cardiovascular diseases symptoms and risk factors (Tejada et al., 2016; Guasch-ferré et al., 2019).

Hydroxytyrosol (HT) is a most potent antioxidant, with $154.16 \mathrm{~g} / \mathrm{mol} \mathrm{M}$ mass found in the olive plant (GranadosPrincipal et al., 2010). HT is naturally derived from the hydrolysis of oleuropein (Tagliafierro et al., 2015) and alternatively, from dopamine metabolism in humans (Rodríguez-Morató et al., 2016). In nature, HT is hydrophilic hence readily absorb in a dose-dependent manner in animals and humans and are excreted in the urine as glucuronide conjugates (Kamil et al., 2020). HT is a well-studied phytochemical for its vascular protection (Hernáez et al., 2017; Nemzer et al., 2019), antioxidant (Adawiyah Razali et al., 2019; Soler-Cantero et al., 2012; Tejada et al., 2016), anti-inflammatory (Chin and Pang, 2017; Ng et al., 2017; Vilaplana-Pérez et al., 2014; Li et al., 2017), anti-atherogenic properties including the inhibition of LDL oxidation (Storniolo et al., 2019); and anti-platelet aggregation (De Roos et al., 2011). A couple of independent research elucidated HT potential in the attenuation of IH development (Xu et al., 2018; Man et al., 2020) However, HT has not been employed in any in vivo model to treat IH. Therefore, we aim to collect the scientific evidence of $\mathrm{HT}$ in the suppression of IH. This systematic review collate in vitro and in vivo studies that elucidate the underlying molecular action of HT in the attenuation of $\mathrm{IH}$.

\section{METHODOLOGY}

\section{Search Strategy}

The selection and screening process were carried out based on PRISMA guideline as presented in Figure 1. A systematic screening through three databases (PubMed, Scopus and Web of Science) were performed. Original articles related to the molecular action of Hydroxytyrosol in intimal hyperplasia were searched using the following keywords: Hydroxytyrosol OR 3,4-dihydroxyphenylethanol AND Intimal hyperplasia OR Neointimal hyperplasia OR Endothelial OR Smooth muscle cells.

\section{Selection Criteria}

Full-text articles published between 2011-2020 in English were included. Only research/original articles were selected while review articles, proceeding abstract, and case studies were excluded. The search included all in vitro and in vivo studies. Titles and abstracts were meticulously screened and only articles that correlate to the molecular and cellular mechanism of action of Hydroxytyrosol in intimal hyperplasia were selected.

\section{Data Extraction and Management}

Two independent reviewers thoroughly screen the selected research articles. All related articles from the database searches were 


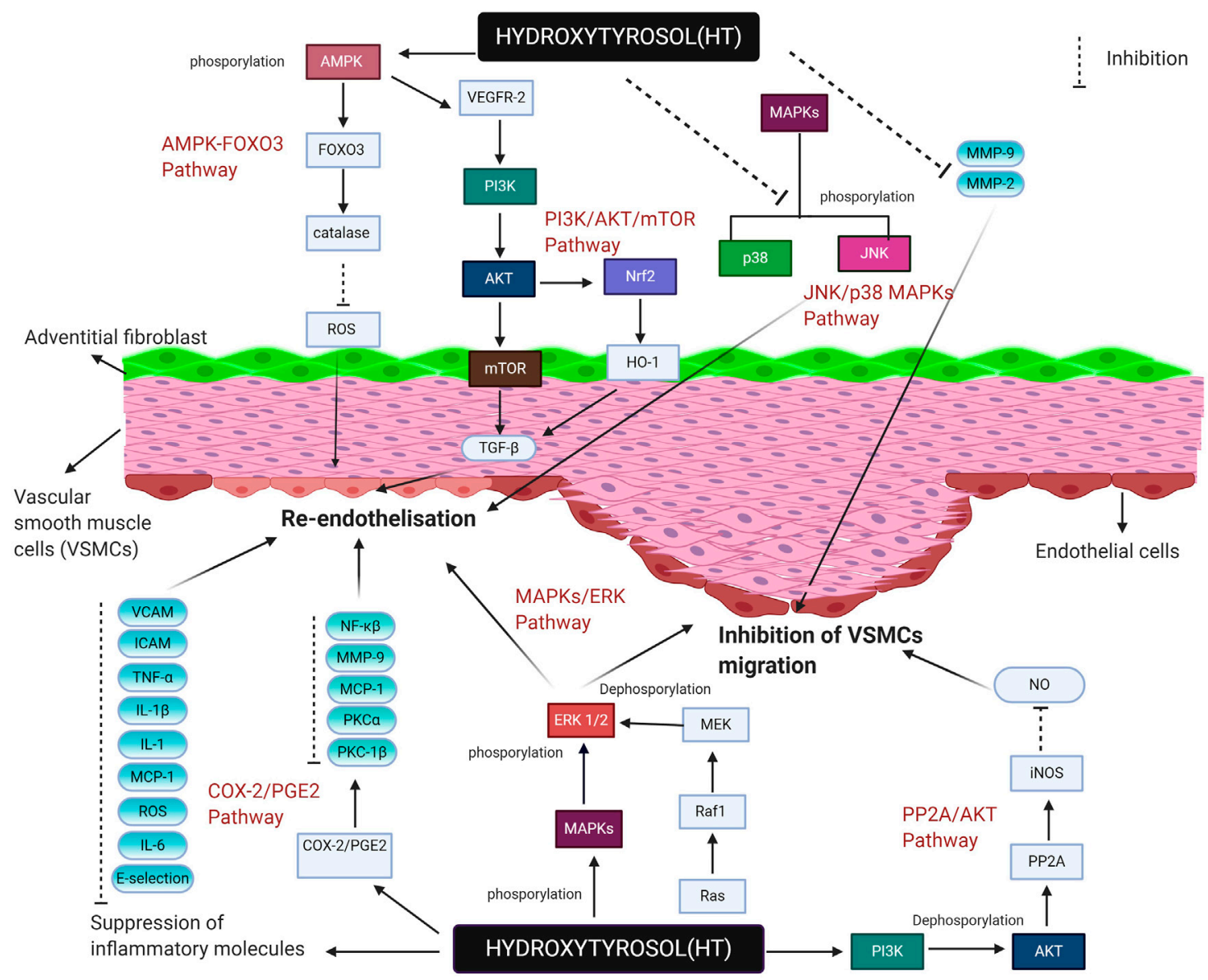

FIGURE 2 | Hydroxytyrosol regulating key genes, inflammatory molecules and pathways in reendotelisation and inhibition of VSMCs

combined and duplicates were removed. The rest of the articles were screened further to meet the selection criteria. The title was first screened, follow by the abstracts for relevance to the selected topic. Unrelated articles that do not fall into the inclusion criteria were removed. The extracted data are tabulated concisely as follows: 1) Reference 2) Aim 3) Cells and Treatment 4) Test(s) 5) Finding(s) 6) Signaling molecules/Pathways 7) Conclusion/correlation with IH.

\section{Quality Evaluation}

The quality of the selected studies was validated using a modified version of Office of Health Assessment and Translation (OHAT). The checklist is designed as presented in Table 3 to evaluate the potential risk of bias of both in vivo and in vitro studies by assessing 1) reporting bias, 2) performance bias, 3) detection bias, and 4) selection bias.

\section{RESULT}

\section{Search Results}

Initially, a total of 335 articles were identified from all database search and 216 articles remained after the removal of duplicates.
The reviewers validate selected articles independently according to designed inclusion and exclusion criteria to minimize bias. Screening of title and abstract were done twice and a total of 35 papers were identified. During the final screening of the full text, 11 non-related articles, and 3 articles that used nonvascular cells were excluded. In the end, a total of 19 in vitro and 4 both in vitro and in vivo studies were selected for the review. Figure 1 shows the selection and screening process based on PRISMA guidelines.

\section{Study Characteristics}

Three electronic database searches identified 19 in vitro (Table 1) and 4 studies that include both in vivo and in vitro (Table 2) analysis related to the action of HT in enhancing endothelial function and inhibiting proliferation of VMSCs which are involved in the suppression of intimal hyperplasia development. Data extracted from the selected articles is presented in Table 1. Most experiments were conducted utilizing human umbilical vein endothelial cells (HUVECs), human vascular endothelial cells (HVEC) and porcine pulmonary artery endothelial cells (PAECs). However, monocyte cell lines such as U937 and Jurkat were also used in 3 studies. Bovine vascular smooth muscle cells (BVSMVs) and 
TABLE 1 | In vitro studies outcomes.

No References

Aim

Cells and treatment

Tests

Findings

Signaling

Conclusion/correlation
with IH

Pathways

1 Nakbi et al. To investigate the potential of $\mathrm{HT}$ Cells (2011)

$\frac{\text { Cells }}{\text { THP-1 }}$

1. Superoxide anion

1. HT and T reduced superoxide caused by ROS production and MMP-9 expression in PMA induced THP-1

$\mathrm{HT}(1,5,10$ and $50 \mu \mathrm{M})$ and $\mathrm{T}$

$(0.05,0.15,0.5$ and $2 \mathrm{mM})$ for 4

15 and $24 \mathrm{~h}$ followed by addition of PMA $(0.1 \mu \mathrm{M})$

2 Scoditti et al. To study polyphenols effect on (2012) COX-2 and MMP-9 expression induced by pro-angiogenic

1. HUVEC

factor PMA

2. HMEC-1

Treatment

HT $(0.1-50 \mu \mathrm{Mmol} / \mathrm{L})$

3 Lamy et al. To investigate effect of phenolic (2014) compounds toward endothelial cell angiogenesis

\section{$\frac{\text { Cells }}{1 . \text { HUVECS }}$} (HMVECs-d-Ad) Treatment $50 \mu \mathrm{M}$ olive ol compounds for 18 followed by addition of $1 \mu \mathrm{g} / \mathrm{ml}$ VEGF

4 Scoditti et al. To study the HT effect on MMP-9 (2014) expression involved in COX-2/ PGE2 pathway in PMA

$\frac{\text { Cells }}{\text { 1. PBMC }}$

stimulated human monocytes stimulated

2. U937

Treatment

HT (1-10 $\mu \mathrm{mol} / \mathrm{L})$ for $1 \mathrm{~h}$ followed by stimulation with $30 \mathrm{nmol} / \mathrm{L}$ PMA for 0-24 $\mathrm{h}$

catalase activity through AMPK-

Treatment

FOXO3a pathway

production release

2. MMP-9 expression

$$
\begin{aligned}
& \text { and p65 } \\
& \text { expression } \\
& \text { 6. ROS prod }
\end{aligned}
$$

6. ROS production

1. Tube formation

2. Cell proliferation

3. Cell migration

4. VEGFR-2

phosphorylation study

1. MMP-9 and TIMP-1

secretion

2. PGE2 production

3. COX-2, COX-1, PKCa,

PKCb1, NF-KB

expression

4. MMP-9, COX-2, MCP-

1, ICAM-1, IL-1b, TNF-a

gene expression

5. NF-kB activation

6. PKC translocation

1. ROS production

2. Catalase mRNA level

3. Phosphorylation of

AMPKa and AMPK $\beta 1$

4. Protein level of catalase,

FOXO3a and AMPK
1. HT prevented inflammatory tube NF-kB formation and cell migration

2. HT inhibited MMP-9 expression

3. HT inhibited COX-2 activity

4. HT decreased ROS level

5. HT suppressed translocation and transactivation of p65 NF-kB

1. HT suppressed VEGF-induced tube formation

2. HT inhibited cell proliferation

3. HT inhibited phosphorylation of

VEGFR-2

4. HT suppressed phosphorylation

of ERK-1/2 and SAPK/JNK

1. HT suppressed MMP-9

secretion

2. HT reduced MMP-9 mRNA

evels

3. HT suppressed PGE2

production

4. HT inactivated NF-kB

5. HT decreased MCP-1, ICAM-1,

$\mathrm{L}-1 \mathrm{~b}$, and TNF- $a$ mRNA level

6. HT inactivated PKC $\alpha$ and

PKC $\beta 1$

1. HT reduced ROS

2. HT increased catalase

expression

3. HT upregulated $\mathrm{FOXO} 3$

expression and mediated nuclear translocation

4. HT activated AMPK

phosphorylation

2. NF-kB
ROS

HT reduced MMP-9 production that could prevent the migration of smooth muscle cell

HT suppressed the ROS level and $\mathrm{NF}-\mathrm{kB}$ activation that regulates the proliferation of endothelial and smooth muscle cells

1. VEGF 2

2. ERK-1/2

3. SAPK/JNK

HT potently suppressed ERK-1/2, SAPK and JNK pathways involved in endothelial apoptosis

\section{PGE2}

HT exhibits protection agains vascular endothelial inflammation by suppressing inflammatory cytokines and activating COX-2 and PGE2 pathway

HT positively regulated endothelial oxidative defense while prevents endothelial dysfunction and apoptosis by activating AMPKFOXO3 pathways 
TABLE 1 | (Continued) In vitro studies outcomes.

No References

\section{Signaling}

molecules/

Pathways

6 Zrelli et al. To study the effect of (2013) hydroxytyrosol with carbon monoxide-releasing Molecule-2 in prevention of endothelia dysfunction through NO production and $\mathrm{NF} \mathrm{KB}_{\mathrm{K}}$ inactivation

Cells

Treatmen

HT $(1,10$, or 100$) \mu \mathrm{mol} / \mathrm{L}$

1. eNOS,NFkBp65, cleaved

3. cospase-3 exp

2. HT suppressed cellular damage

$\mathrm{NF} K \mathrm{~B}$

3. NO production

4. Cell cytotoxicity

5. Cell morphology

6. NFKB activation

$7 \quad$ Abe et al. (2012)

8 Torul et al. (2020)

$9 \quad$ Fortes et al. To investigate effect of of olive extract on endothelial toxicity induced by hydrogen

$\begin{array}{ll} & \text { peroxide } \\ \text { Fortes et al. } & \text { To investigate effect of }\end{array}$ (2012)

To investigate effect of hydroxytyrosol and tyrosol in preventing inflammator angiogenesis

10 Abate et al. To investigate the effect of $\mathrm{HT}$ in (2020) endothelial vascularization

\section{BVS}

Treatment

HT $(1,10$, or $100 \mu \mathrm{mol} / \mathrm{L})$

Cells

Treatment

HT (1.0-10.0 $\mu \mathrm{mol} / \mathrm{L}$

Cells

1. HUVECS

2. HMECS

3. BAECS

HT $10 \mathrm{mg} / \mathrm{ml}$

$\frac{\text { Cells }}{\text { 1. HUVECs }}$

2. HVECS

Treatment

$(0-160 \mu \mathrm{M})$ for 24 and $48 \mathrm{~h}$ phosphorylation while CORM-2
1. Cell proliferation

2. Cell cycle

3. (ERK) $1 / 2$

phosphorylation

1. Determination of

phenolic compounds

2. Induction of ROS

3. Cell cytotoxicity

1. Cell cytotoxicity

2. Cell migration

3. Tube formation

4. Cell cycle analysis

5. MMP-2 production

1. Cell viability

2. Cell proliferation

3. Wound healing

4. Cell migration

5. Tube formation

6. Angiogenesis protein

expression
3. HT inhibited apoptotic

morphology changes and

apoptotic cell death

4. HT alone and HT + CORM-2

reduced NFkBp65 protein level

5. HT + CORM-2 increased Enos

phosphorylation

6. HT + CORM-2 increased NO

release

7. HT + CORM-2 blocked

activation of caspase-3

8. HT alone inhibited NFkBp65

enhanced it

9. $\mathrm{HT}+\mathrm{CORM}-2$ inactivates $\mathrm{NF} K \mathrm{~B}$

1. $H T$ inhibited cell proliferation

2. HT disrupted cell cycle and

controlled over proliferation

3. HT inhibited ERK1/2

phosphorylation

1. HT suppressed cell toxicity

2. HT decreased ROS production

1. HT inhibited cell proliferation

2. HT inhibited cell migration

3. HT suppressed tube formation

4. HT enhances apoptosis

5. HT regulated cell cycle

6. HT inhibited MMP-2 activity

1. HT safe for cells up to $160 \mu \mathrm{M}$

2. HT enhanced wound healing

process

3. HT stimulated HUVEC migration

4. HT upregulated migration and

adhesion related protein

expression such as ROCK, MMP-

2, Phospho-Src, Src, Phospho

Erk1/2, Erk1/2, RhoA, Rac1 and

Ras

5. HT enhanced tube formation

6. HT upregulated VEGF) receptor

2

7. eNOS, PI3-Kinase, m-TOR,

AMPK and Akt

\section{Conclusion/correlation}

with IH

HT + CORM-2 potentially inhibited endothelial apoptosis by inhibiting caspase 3 and $\mathrm{NFkB}$ pathway while supported vascular healing through NO production

HT has potential to inhibit intimal hyperplasia by reducing migration and proliferation of SMC via blocking cell cycle regulated by ERK1/2 phosphorylation

HT shown to decrease ROS generation in endothelial which could promote vascular healing

$H T$ regulated endothelial cell cycle while decreased production of MMP-2 that possibly could prevent smooth muscle cells migration

HT positively regulated vascular remodeling by promoting reendothelization and wound healing by activating PI3K/AKT/ mTor pathways 
TABLE 1 | (Continued) In vitro studies outcomes.

No References

Aim

Cells and treatment

Tests

Findings

Signaling

Conclusion/correlation

11 Wang et al. (2018)

To assess the effect of $\mathrm{HT}$ on autophagosis of VAFs and its related signaling pathways

$\begin{array}{ll}\text { Cells } & \text { 1. Cell viability } \\ \text { VAFs } & \text { 2. SIRT1 siRNA level } \\ \text { Treatment } & \text { 3. Autophagy related }\end{array}$

1. HT was shown no cytotoxicity

up to $100 \mu \mathrm{M}$

HT (12.5, 25, 50, 100, 200 and $400 \mu \mathrm{M})$ for $1 \mathrm{~h}$ followed by 3. Autophagy related

2. HT upregulated conversion of

4. Inflammatory cytokines of LC3 mRNA in VAFs stimulated induction of TNF- $\alpha(5 \mathrm{ng} / \mathrm{ml})$ level for $24 \mathrm{~h}$

12 Cheng et al. (2017)

To study the potential of HT together with PEMFs on HUVECs proliferation

13 Kouka et al. To examine antioxidant property (2017) fraction

Cells

Treatment

PEMFs at days $0,1,2,3$ or 4 , or treated with $\operatorname{HTY}(0,10,30,50$, $100,150 \mu \mathrm{M}$ ) at day 2 , or treated with a combination on days $0,1,2$ or 4

\section{Cells}

. EA. hy926

2. $\mathrm{C} 2 \mathrm{C} 12$

Treatment $\mathrm{HT}(0-40 \mu \mathrm{g} / \mathrm{ml})$

14 Kitsati et al. To assess the potential of HT in (2016)

\section{rescuing cells from oxidative}

stress induced by $\mathrm{H}_{2} \mathrm{O}_{2}$

\section{Jurkat cells \\ Treatment}

$\overline{\mathrm{HT}}(0.05$ and $0.1 \mathrm{mM})$ for $30 \mathrm{~min}$ with TNF-a

3. HT increased protein level and mRNA expression of Beclin1

4. HT regulated the expression of SIRT1

5. HT and SIRT1 shown

compatibility in molecular docking

6. HT activated Akt/mTOR

signaling pathway

7. HT decreased TNF- $\alpha$ induced

inflammatory cytokine IL-1

1. HTY + PEMF increases cell

proliferation

1. Cell viability
2. Cell migration

3. Cell apoptosis

2. HTY + PEMF enhanced cell

migration

3. HTY + PEMFs prevented

apoptosis

4. HTY increases mRNA and

protein level of Akt, mTOR and

TGF- $\beta$, but not p53

1. Extraction of TPF from 1. HT exhibited highest antioxidant DPPH

EVOO

2. HT reduced ROS

2. Purification of $H T$ from

TPF

3. HT increased GSH

1. Akt

2. $\mathrm{MTOR}$

3. TGF- $\beta$

assay

4. Cell viability

5. Assessment of GSH

5. Assessment
and ROS levels

1. Comet assay

2. Labile iron level

3. $\mathrm{H}_{2} \mathrm{O}_{2}$ generation

\section{JNK}

1. $\mathrm{HT}$ inhibited $\mathrm{H}_{2} \mathrm{O}_{2}$ induced labile iron level

2. Hydroxytyrosol inhibits $\mathrm{H}_{2} \mathrm{O}_{2}$ induced and mitochondrial-

mediated apoptosis

3. Hydroxytyrosol inhibits $\mathrm{H}_{2} \mathrm{O}_{2}$ -

induced apoptosis

4. inhibits $\mathrm{H} 2 \mathrm{O}$

5. HT inhibited phosphorylation

and activation of the JNK and p38

MAPKs molecules/

Pathways

1. SIRT1 2. Akt/mTOR

with IH

Hydroxytyrosol promoted

autophagy of VAFs via SIRT1

signaling pathway and inhibited

inflammatory cytokines in vascular

inflammation pathophysiology

PEMFs and HTY enhanced

endothelial migration and

proliferation that could promote

reendothelization in vascular

remodeling

$H T$ found to have decreased ROS and increased GSH which possibly enhance endothelial proliferation and functioning

2. p38 MAPKs

HT prevented cellular apoptosis by nactivating JNK and p38 MAPKs pathway 
TABLE 1 | (Continued) In vitro studies outcomes.

\section{Zrelli et al. To examine the action of} (2015) hydroxytyrosol in the vascular wound healing mechanism

\section{Cells}

$\frac{\text { Treatment }}{0-24 \mathrm{~h}}(10-100 \mu \mathrm{M})$

\section{Expre}

Nrf2

2. Wound healing

1. Cell migration

2. Cell viability

3. NO production

VSMCs proliferation
To assess the proliferation and protective effect of $\mathrm{HT}$ on oxidative injury induced VECs injury

To evaluate the effect of hydroxytyrosol and its plasma metabolites toward endothelial protection

\section{$\frac{\text { Cells }}{\text { PPAECs }}$ \\ Treatment}

HT (10-100 $\mu \mathrm{M}$ ) for $24 \mathrm{~h}$ followed by $0-7003 \mathrm{M}$ ) of $\mathrm{H}_{2} \mathrm{O}_{2}$ for $24 \mathrm{~h}$

\section{Cells

Treatmen

$\mathrm{HT}(1,2,5$, and $10 \mu \mathrm{M}) \mathrm{co}-$

incubated with TNF $-a(10 \mathrm{ng} / \mathrm{ml})$ for 18 and $24 \mathrm{~h}$

To investigate the HT-3Os effects Cells on endothelial-to-mesenchymal 1. EC

$\begin{array}{ll}\text { on endothelial-to-mesenchymal } & \text { 1. EC } \\ \text { transition (EndMT) in the inflamed } & \text { 2. HUVEC }\end{array}$ endothelium
3. HREC

1. $\mathrm{IL}-1 \beta(10 \mathrm{ng} / \mathrm{ml})$ with or without HT-3Os (10 $\mu \mathrm{M}$, every $24 \mathrm{~h}$ for

7 days

\section{Cell viability \\ 2. Wound healing}

3. HO-1 mRNA

expression

4. phosphorylation of Akt, P38 MAPK, and ERK1/2 5. ROS production

1. HT metabolites production 2. Adhesion molecules production

Chemokine protein production

4. Cytotoxicity 1. Morphology evaluation 2. Immunomarkers detection

3. Cytoplasmic and nuclear protein detectio 4. miRNA expression analysis 5. Cytotoxicity

$\begin{array}{ll}\text { 1. HT inclined HO-1 mRNA and } & \text { 1. PI3K } \\ \text { protein level } & \text { 2. ERK } \\ \text { 2. HT induced HO-1 expression } & \text { 3. Nrf2 } \\ \text { supported by PI3K/Akt and ERK1/ } & \\ \text { 2 } \mathrm{H} \text {. } & \\ \begin{array}{ll}\text { 3. HT mediated Nrf2 expression } \\ \text { and nuclear localization }\end{array} \\ \begin{array}{ll}\text { 1. HT decreased the number of } & \text { 1. Akt } \\ \text { viable VSMCs either in the } & \text { 2. PPA }\end{array}\end{array}$

pros Vives either in the

2. HT promotes VSMCs apoptosis

3. HT increased NO production

4. HT increased iNOS protein

expression

5. HT dephosphorylate Akt

6. PP2A mediated HT induced Akt phosphorylation

1. HT enhanced cell proliferation 2. HT repaired wound healing

3. HT prevented $\mathrm{H}_{2} \mathrm{O} 2$-Induced cytotoxicity

2. MAPK

HT protects VECs from oxidative damage through activation of the PI3K/Akt and ERK1/2 pathways

Akt, p38 MAP

5. HT accumulates Nrf2 in nucleus 6. HT reduced ROS generation

7. HT increased mRNA and protein level of $\mathrm{HO}-1$

1. $H T$ and $H T$ metabolites reduced E-selectin, P-selectin, VCAM-1, and ICAM-1

2. HT metabolites only reduced MCP-1

\section{HT enhanced wound healing} process in endothelial through activating expression of $\mathrm{HO}-1$ and Nrf2

HT prevents VSMCs apoptosis through NO production and Akt dephosphorylation via activation of PP2A

$\mathrm{HT}$ and $\mathrm{HT}$ metabolites exhibited vascular protection by reducing endothelial inflammation cytokines

1. HT-3Os reverses EndMT$1 \beta$ $\beta$

HT-3Os restores let-7 miRNA expression and inhibits TGF- $\beta$ signaling

3. HT-3Os upregulated CD31 in IL-

$1 \beta$ induced HUVEC and HREC

4. HT-3Os decreased fibroblast markers as FN1 and VIM or SMCin IL- $1 \beta$ induced HUVEC and HREC) 5. HT-3Os upregulated $\mathrm{NOTCH} 3$ and MMP2 and MMP9 
human microvascular endothelial cells (HMVECs) were utilized in 2 studies. Human microvascular cell line, bovine aorta endothelial cells (BAECs), human peripheral blood cells, myoblast, rat vascular smooth muscle cells, and vascular adventitia fibroblast were also utilized. Two in vivo studies were conducted on mice while one was done in a rat model.

\section{Quality Evaluation}

Risk bias analysis was conducted using modified version of Office of Health Assessment and Translation (OHAT). Overall, twentyone out of twenty-three studies showed low risk bias. Two in vitro, two in vivo and one in vitro and ex vivo studies showed low risk of bias when they fulfill the selection criteria and reported all outcomes. In contrast, two studies showed high substantial risk of bias due to insufficient sample number and unclear adverse event reporting. A summary of risk bias analysis presented in Table 3.

\section{HT Role as an Antioxidant}

Antioxidant potential of HT comes from its chemical presence of hydroxyl $(\mathrm{OH})$ groups in the ortho position. These $\mathrm{OH}$ groups are responsible in forming stable hydrogen bonds by scavenging reactive oxygen species (ROS) such as hydrogen peroxide $\left(\mathrm{H}_{2} \mathrm{O}_{2}\right)$, superoxide ion $\left(\mathrm{O}_{2}^{-}\right)$, hydroxyl radical $\left(\mathrm{OH}^{-}\right)$, and reactive nitrogen species (RNS) (Napolitano et al., 2010). HT regulates vascular homeostasis by balancing cellular oxidation stress and in addition to that, treatment with HT increase the production of nitric oxide (NO) which directly plays a crucial role in endothelial cells (ECs) functioning (Sandoo et al., 2010) such as inhibition of inflammation, cell adhesion (Reglero-Real et al., 2016), platelets interactions (Hamilos et al., 2018) as well as maintaining vessel tone (Norton and Popel, 2016).

Imbalance cellular redox reactions in ECs arise from vascular complications like thrombosis (Yang et al., 2017), intimal growth (Nedeljkovic et al., 2003), inflammation, and infarction (Pober and Sessa, 2007). These events are likely activate transcription factors which mediate the secretion of inflammatory factors and cells to the site of inflammation which eventually, delays the healing process (Martinon, 2010; Yang et al., 2017). Interestingly, Pi et al. showed that organic compound extracted from plant i.e. apocynin reduces endogenous ROS level in mice with carotid injury that subsequently suppressed the secretion of pro-inflammatory molecules and VSMC proliferation (Pi et al., 2013). Similarly, heart failure drug like simvastatin and Ivabradine reduces the generation of ROS in $\mathrm{IH}$ progression in hyperlipidaemic rabbits (Koniari et al., 2016).

These findings strongly support the correlation between oxidation machinery and the prevention of IH. From our database search, 9 studies reported that HT efficiently prevented ROS production (Nakbi et al., 2011; Zrelli et al., 2011a; Zrelli et al., 2011b; Scoditti et al., 2012; Zrelli et al., 2013; Kouka et al., 2017; Torul et al., 2020). HT was also reported to be able to phosphorylate endothelial nitric oxide synthase (eNOS) which increases nitric oxide (NO) synthesis that essentially needed for vascular integrity and protection (Tousoulis et al., 2011; Zhao et al., 2015; Loscalzo and Jin,
2010). This effect could potentially promote reendothelization in $\mathrm{IH}$ repair.

In addition to that, $\mathrm{HT}$ also protect cells from $\mathrm{H}_{2} \mathrm{O}_{2}$ induced cytotoxicity and apoptosis by decreasing superoxide release (Nakbi et al., 2011; Torul et al., 2020) while activating JNK and p38 MAPKs pathways (Kitsati et al., 2016). Interestingly, a particular study by Zrelli found that HT activate the AMPKFOXO3 pathway by enhancing catalase activity to reduce oxidative stress (Zrelli et al., 2011b). Expression of FOXO3 appears to protect cells from oxidative injury by regulating the expression of the antioxidant enzyme such as catalase and peroxiredoxin (Hou et al., 2010; Olmos et al., 2009). Similarly, another set of studies stated AMPK directly activates FOXO3 transcriptional activity to provide cellular resistance toward oxidative stress (Greer et al., 2007; Li et al., 2009).

\section{HT Reduces Vascular Inflammatory Markers}

Endothelial injury is a precursor for intimal hyperplasia (Garg and Hassid, 1989; de Vries and Quax, 2018). Inflammatory cytokines, chemokines, immune cells, and platelets are recruited to the site of injury to initiate repair mechanism which starts off with vascular inflammation and followed with healing process that are regulated by the immune system to maintain vascular health (D'Angelo et al., 2020). However, prolonged exposure to inflammatory molecules has a detrimental effect on vascular cells. Especially, during vascular injury, the secretion of ICAM-1 and MCP-1 attract platelet and leukocyte to the injured site. Gradually, the activated platelets trigger Thromboxane A2 and PDGF release which causes the VSMC to proliferate and migrate (Davies and Hagen, 1989; Huang et al., 2002). Thus, downregulating inflammatory factors and mediators potentially could prevent further progression of $\mathrm{IH}$. Olive oil extracts have been shown to decrease the inflammatory activation in endothelial cells (Burja et al., 2019).

In ECs inflammation, nuclear factor-kappa B (NFkB) transcription factor regulates inflammatory mediators such as MCP-1, VCAM-1, ICAM-1, and E-selectin which recruits leukocytes, IL-6, and IL-8. (Pamukcu et al., 2011). From our systematic search, Scoditti et al. found that HT treatment decrease the expression of MMP-9, ICAM-1, IL-1b, TNF- $\alpha$, and COX-2 by inactivating NF- $\kappa \beta, P K C \beta 1$, and PKCa in PMA activated human monocytes (Scoditti et al., 2014). Upon consumption, HT metabolized into glucuronide, sulfate methyl and methyl-sulphate conjugates (Kotronoulas et al., 2013; Rubió et al., 2014). It is crucial to test biological activity of HT metabolites together with HT assessing in vascular protection ability of HT. Catalan and colleagues synthesized physiological HT metabolites using Caco- 2 cells. They reported that HT with its metabolites decrease inflammatory mediatorssuch as E-selectin, P-selectin, ICAM-1, and VCAM-1 but HT metabolite alone could only decrease MCP-1 level (Catalán et al., 2015). They further elucidate HT and HT metabolites potential in rat and endothelial cell model where they reported that HT and HT derivate supplemented aorta, stained less for E-selectin, MCP-1, and 
TABLE 2 | In vitro and in vivo studies outcome.

\begin{tabular}{|c|c|c|c|c|c|c|c|}
\hline 1 & $\begin{array}{l}\text { García } \\
\text { et al. } \\
\text { (2017) }\end{array}$ & $\begin{array}{l}\text { To study effects of } \\
\text { Hydroxytyrosol in } \\
\text { endothelial cell expressing } \\
\text { extracellular matrix } \\
\text { remodeling enzymes in } \\
\text { inhibition of angiogenesis }\end{array}$ & $\begin{array}{l}\text { Animal and Cells } \\
\text { 1. Rats } \\
\text { 2. BAECs } \\
\frac{\text { Treatment }}{\text { In vitro-HT } 0-800 \mathrm{nmol} \text { ) and }} \\
1 \mathrm{mM} \text { of HT for } 24 \mathrm{~h} \text { cells } \\
\text { In vivo-HT } 31.2,62.5,125 \text { and } \\
250 \mu \mathrm{m}) \text { for } 48 \text { hours }\end{array}$ & $\begin{array}{l}\text { 1. Ex vivo rat aortic } \\
\text { ring assay } \\
\text { 2. In vivo } \\
\text { chorioallantoic } \\
\text { membrane (CAM) } \\
\text { assay } \\
\text { 3. mRNAs for some } \\
\text { extracellular matrix } \\
\text { remodeling } \\
\text { enzymes }\end{array}$ & $\begin{array}{l}\text { 1. HT reduced MMP-1 } \\
\text { and MMP-2, uPA } \\
\text { mRNA expression } \\
\text { 2. HT inhibit ex vivo } \\
\text { angiogenesis, yet } \\
\text { endothelial } \\
\text { outgrowing observed } \\
\text { 3. HT prevented in } \\
\text { vivo angiogenesis }\end{array}$ & & $\begin{array}{l}\text { HT decreased } \\
\text { expression of } \\
\text { extracellular matrix } \\
\text { remodeling enzyme that } \\
\text { could supress migration } \\
\text { of smooth muscle cells }\end{array}$ \\
\hline 2 & $\begin{array}{l}\text { Catalán } \\
\text { et al. } \\
(2018)\end{array}$ & $\begin{array}{l}\text { To study the potential of } \\
\text { hydroxytyrosol }(\mathrm{HT}) \text { and its } \\
\text { plasmatic metabolites } \\
\text { (HTmet) in enhancement of } \\
\text { endothelial function }\end{array}$ & $\begin{array}{l}\frac{\text { Animal and cells }}{1 . \text { Apolipoprotein } \mathrm{E} \text { knockout }} \\
\text { mice } \\
\text { 2. HAEC } \\
\text { 3. Jurkat } \\
\text { Treatment } \\
\text { Invivo- } 10 \mathrm{mg} / \mathrm{kg} / \text { day of HT } \\
\text { derivatives for } 12 \text { weeks } \\
\text { Invitro-cells }(1,2 \text { and } 5 \mu \mathrm{M}) \\
\text { and TNF- } \alpha(10 \mathrm{ng} / \mathrm{ml}) \text { for } 24 \mathrm{~h}\end{array}$ & $\begin{array}{l}\text { 1. VCAM-1, } \\
\text { E-selectin, MCP-1, } \\
\text { ICAM-1 expression } \\
\text { 2. Human } \\
\text { Phospho-MAPK } \\
\text { Array } \\
\text { 3. NF-B (p65) } \\
\text { expression }\end{array}$ & $\begin{array}{l}\text { 1. Mice aortas stained } \\
\text { less for E-selectin, } \\
\text { MCP-1, and ICAM-1 } \\
\text { 2. HTmet reduced } \\
\text { Jurkat T adhesion } \\
\text { 3. HTmet decreased } \\
\text { E-selectin and VCAM- } \\
1 \text { mRNA expression in } \\
\text { HAECs } \\
\text { 4. HT and HTmet } \\
\text { decreased CREB, } \\
\text { ERK, JNK pan, JNK, } \\
\text { p388, p70 S6 kinase }\end{array}$ & $\begin{array}{l}\text { 1. ERK } \\
\text { 2. JNK } \\
\text { 3. MAPK }\end{array}$ & $\begin{array}{l}\text { HT and its metabolites } \\
\text { shown to have } \\
\text { endothelial protection } \\
\text { potential which } \\
\text { regulated by the MAPK } \\
\text { pathway }\end{array}$ \\
\hline 3 & $\begin{array}{l}\text { Yaoa } \\
\text { et al. } \\
\text { (2019) }\end{array}$ & $\begin{array}{l}\text { To examine the potential of } \\
\text { hydroxytyrosol acetate on } \\
\text { vascular endothelial } \\
\text { inflammation mechanism }\end{array}$ & $\begin{array}{l}\text { Animal and Cells } \\
\text { 1. Specific Sirt6 knockout } \\
\text { mice hypercholesteraemic } \\
\text { 2. HUVECs } \\
\text { Treatment } \\
\text { Invivo- P-407 }(0.5 \mathrm{~g} / \mathrm{kg}), \mathrm{P} \text { - } \\
407+\mathrm{HT}(5,10,20 \mathrm{mg} / \mathrm{kg}) \text {, } \\
\text { and P-407+HT-AC }(5,10 \text {, } \\
20 \mathrm{mg} / \mathrm{kg}) \text { groups } \\
\text { Invitro-HT or HT-AC }(25,50 \text {, } \\
\text { or } 100 \mu \text { mol/L) for } 1 \mathrm{~h} \text {, and } \\
\text { then stimulated with TNF } \\
\text { (10 ng/ml) for } 8 \mathrm{~h}\end{array}$ & $\begin{array}{l}\text { 1. Cell viability } \\
\text { 2. SOD, MDA and } \\
\text { ROS level } \\
\text { 3. SIRT6 siRNA } \\
\text { transfection } \\
\text { 4. SIRT6 and PKM2 } \\
\text { expression } \\
\text { 5. HT-AC molecular } \\
\text { docking }\end{array}$ & $\begin{array}{l}\text { 1. HT and HT-AC } \\
\text { decreased TNF and } \\
\text { IL1B in mice serum } \\
\text { 2. HT and HT-AC } \\
\text { decreased mRNA } \\
\text { expression of II-b, II6 } \\
\text { and Ccl2 and TNF } \\
\text { 3. HT and HT-AC } \\
\text { decreased mRNA } \\
\text { expressions of IL1B, } \\
\text { IL6 and CCL2 in } \\
\text { HUVECs } \\
\text { 4. HT-AC increased } \\
\text { SOD while decreased } \\
\text { MDA and ROS level in } \\
\text { TNF- induced } \\
\text { HUVECs } \\
\text { 5. HT-AC decreased } \\
\text { TNFRSF1A protein } \\
\text { and mRNA in } \\
\text { HUVECs } \\
\text { 6. HT-AC upregulated } \\
\text { SIRT6 protein and } \\
\text { mRNA expression in } \\
\text { mice } \\
\text { 7. Molecular docking } \\
\text { shown good } \\
\text { compatibility between } \\
\text { HT-AC and SIRT6 } \\
\text { 8. HT-AC decreased } \\
\text { expression of PKM2 in } \\
\text { mice and TNF- } \\
\text { stimulate HUVECs }\end{array}$ & 1. PKM2 & $\begin{array}{l}\text { HT and HT-AC exhibited } \\
\text { protection against } \\
\text { endothelial inflammation } \\
\text { in mice and HUVECs } \\
\text { cells by mediating } \\
\text { PKM2 signaling } \\
\text { pathway }\end{array}$ \\
\hline 4 & $\begin{array}{l}\text { Fuccelli } \\
\text { et al. } \\
\text { (2018) }\end{array}$ & $\begin{array}{l}\text { To study the effect of HT in } \\
\text { inflammatory markers } \\
\text { Cyclooxygenase- } 2 \text { (COX2) } \\
\text { And tumor necrosis factor } \\
\text { alfa (TNF- } \alpha \text { ) and oxidative } \\
\text { stress reduction in vivo } \\
\text { systematic inflammation } \\
\text { model }\end{array}$ & $\begin{array}{l}\frac{\text { Animal }}{\text { Balb/c mice }} \\
\frac{\text { Treatment }}{1 . \mathrm{HT}(40 \text { and } 80 \mathrm{mg} / \mathrm{kg})} \\
\text { 2. LPS induction }(50 \mu \mathrm{g} / \\
\text { mouse) }\end{array}$ & $\begin{array}{l}\text { 1. COX2 mRNA } \\
\text { detection } \\
\text { 2. TNF-a cytokine } \\
\text { determination } \\
\text { 3. DNA damage } \\
\text { assessment } \\
\text { 4. Antioxidant } \\
\text { plasma power } \\
\text { quantification }\end{array}$ & $\begin{array}{l}\text { 1. HT inhibits the } \\
\text { COX2 gene } \\
\text { expression } \\
\text { 2. HT reduces the } \\
\text { TNF-a cytokine } \\
\text { secretion } \\
\text { 3. HT improves the } \\
\text { antioxidant power of } \\
\text { plasma } \\
\text { 4. HT prevents the } \\
\text { DNA damage induced }\end{array}$ & $\begin{array}{l}\text { 1. COX2 } \\
\text { 2. TNF- } \alpha\end{array}$ & $\begin{array}{l}\text { HT inhbited LPS } \\
\text { induced COX2 } \\
\text { expression, TNF- } \alpha \\
\text { production and the DNA } \\
\text { damage while enhance } \\
\text { antioxidant potential of } \\
\text { plasma in vivo model }\end{array}$ \\
\hline
\end{tabular}


Abbreviations: THP-1, human monocyte cell line; U937, Monocytic cell line; HUVECs, Human umbilical vein endothelial cells; HMEC-1, Human microvascular endothelial cell line; PBMC, Human peripheral blood mononuclear cells; PPAECs, Porcine pulmonary artery endothelial cells; BVSMC, Bovine Vascular smooth muscle cells; HMECs, Human microvascular endothelial cells; VAFs, vascular adventitial fibroblasts; HVECs, Human vascular endothelium cells; BAECs, Bovine aorta endothelial cells; HAECs, human aortic endothelial cells; EA, hy926-endothelial cells; C2C12, myoblasts cells; HREC, Human retinal endothelial cells; RVSMCs, Rat Vascular smooth muscle cells; PMA, phorbol myristate acetate; MMP, matrix metalloproteinase; ROS, Reactive oxygen species; COX-2, cyclooxygenase 2; NF- $\kappa \beta$, nuclear factor kappa-light-chain-enhancer of activated B cells; MCP-1, monocyte chemoattractant protein-1; ICAM-1, intercellular adhesion molecule-1; VCAM-1, vascular cell adhesion molecule-1; IL-1 $\beta$, interleukin-1 $\beta$; TNF- $\alpha$, tumour necrosis factor- $\alpha$; HMVECs-d-Ad, Human dermal microvascular endothelial cells; VEGF, Vascular endothelial growth factor; prostaglandin (PG)E2; protein kinase C (PKC); FOXO3a, forkhead transcription factor 3a; AMPK-AMP, activated protein kinase; Akt, protein kinase B; CORM-2, Carbon Monoxide-Releasing Molecule-2; PEMF, Pulsed electromagnetic fields; mTOR-mechanistic target of rapamycin; TGF- 31 , Transforming growth factor; MAPK, mitogen-activated protein kinase; EndMT, Endothelial-to-mesenchymal transition; HT-3Os, plasma metabolite HT-3O sulfate; FGFR1, fibroblast growth factor receptor 1

ICAM-1. Furthermore, they found that HT and HT metabolites provide endothelial protection through regulation of ERK, JNK, and MAPK interrelated pathways (Catalán et al., 2018). Moreover, Hydroxytyrosol acetate (HT-Ac), were also found to be able to suppress inflammatory response by upregulating SIRT-6 expression in hypercholesterolemic mice and TNF- $\alpha$ treated HUVECs. These studies shed light on the activation of TNFRSF1A and PKM2 pathways which are responsible for antiinflammatory activity (Yao et al., 2019) thus proves HT inhibits inflammatory angiogenesis.

Inflammatory angiogenesis contribute immensely in the formation of tumor vasculature. Tumor angiogenesis produces new blood vessels from existing vessels to supply nutrients and oxygen to tumor cells (Aguilar-Cazares et al., 2019). HT successfully inhibited inflammatory angiogenesis in phorbol myristate acetate (PMA) stimulated endothelial cells through inhibition of proinflammatory enzyme cyclooxygenase (COX)2 and matrix degrading enzymes matrix metalloproteinases (MMPs) which are proinflammatory mediators in cancer and atherosclerosis (Fortes et al., 2012; Scoditti et al., 2012).

\section{HT Enhances Re-endothelization}

Re-endothelization is a prime event in IH repair. Delay in reendothelization results in non-successful vascular interventions. Abate et al. reported that HT promote angiogenesis and wound healing in HUVECs cells via activating PI3K/AKT/mTOR pathways while upregulating the migration and adhesionrelated protein expression (Abate et al., 2020). In another study, HT combined with pulsed electromagnetic field treatment, enhanced HUVECs migration and proliferation via regulation of Akt, mTOR, and TGF- $\beta$ pathways (Cheng et al., 2017). Besides, two independent research by Zrelli et al. (2011b, 2015) demonstrates HT action of vascular healing through heme oxygenase-1 (HO-1) activation. High HO-1 expression protects cells from endothelial injury (Marcantoni et al., 2012; Kim et al., 2013). Additionally, they also reported that HT promotes vascular healing by stimulating the Nrf2 pathway which upregulates expression of $\mathrm{HO}-1$ that is supported by $\mathrm{PI} 3 \mathrm{~K}$, Akt, Erk 1/2. Lamy and colleagues, revealed that HT prevent endothelial apoptosis by suppressing ERK-1/2, SAPK and JNK pathways (Lamy et al., 2014).

\section{HT Inhibit VMSCs Proliferation and Migration}

Proliferation and migration of VMSCs are huge contributors to intimal thickening. Naturally, VSMCs exist in both contractile and synthetic phenotypes which are responsible to maintain vascular homeostasis (Michel et al., 2012; Basatemur et al., 2019). Endothelial injury tends to trigger generation of inflammatory factors such as platelet-derived growth factor (PDGF), fibroblast growth factor (FGF), and transforming growth factor-beta (TGF $\beta$ ), which accelerate the migration of VMSCs into the intima layer (Lindqvist et al., 2001). HT promote VMSCs apoptosis via the production of $\mathrm{NO}$ and subsequent inactivation of Akt mediated by PP2A pathway in PDGF induced rat VMSCs (Zrelli et al., 2011a).

Regulation of VSMCs proliferation determines by MAPKs family members such as c-Jun $\mathrm{N}$ terminal kinase (JNK), extracellular signal-regulated kinase $1 / 2$ (ERK), and p38 (Xu et al., 2018). MAPK chains also promote PDGF-stimulated VSMCs migration in the vascular injury model (Zhan et al., 2003). In a study by Liu et al., sulphur dioxide prevented VSMCs proliferation by inactivating Erk/MAP kinase pathway (Liu et al., 2014). Therefore, HT successfully inhibit bovine VMSCs proliferation in the same manner by disrupting the cell cycle regulated by ERK 1/2 (Abe et al., 2012).

On another hand, Matrix Metalloproteinases (MMP) are crucial extracellular matrix (ECM) components in maintaining vessel integrity and angiogenesis (Raffetto and Khalil, 2008). Amongst the different type of MMPs, MMP-2 were shown to enhanced VMSCs migration by disrupting the ECM in an in vitro model (Belo et al., 2015). Therefore, HT's ability to inhibit MMP2 expression (Fortes et al., 2012) could therefore suppress VSMCs migration. Just as important, expression of MMP-9 that breaks the barrier between VSMCs and ECs were found to be downregulated by HT treatment (Nakbi et al., 2011; Scoditti et al., 2012; Scoditti et al., 2014). Phenotype switching of VSMCs from contractile to synthetic, marks the beginning of VSMCs remodeling (Wadey et al., 2018). In a past study, Resveratrol stimulate differentiation of VSMCs and inhibit migration by activating SIRT1 and AMPK (Thompson et al., 2014). In the same way, HT regulate the expression of SIRT1 in TNF- $\alpha$ stimulated vascular adventitia fibroblast (VAFs). HT and SIRT1 were shown to have good compatibility (Wang et al., 2018). These findings thus support HT ability in prevention of excessive vascular remodeling.

\section{DISCUSSION}

Ethnopharmacology has been an ever-growing field especially in the discovery of new compound in treatments of various diseases. Linking our ancestor knowledge in medicinal plants and giving it 


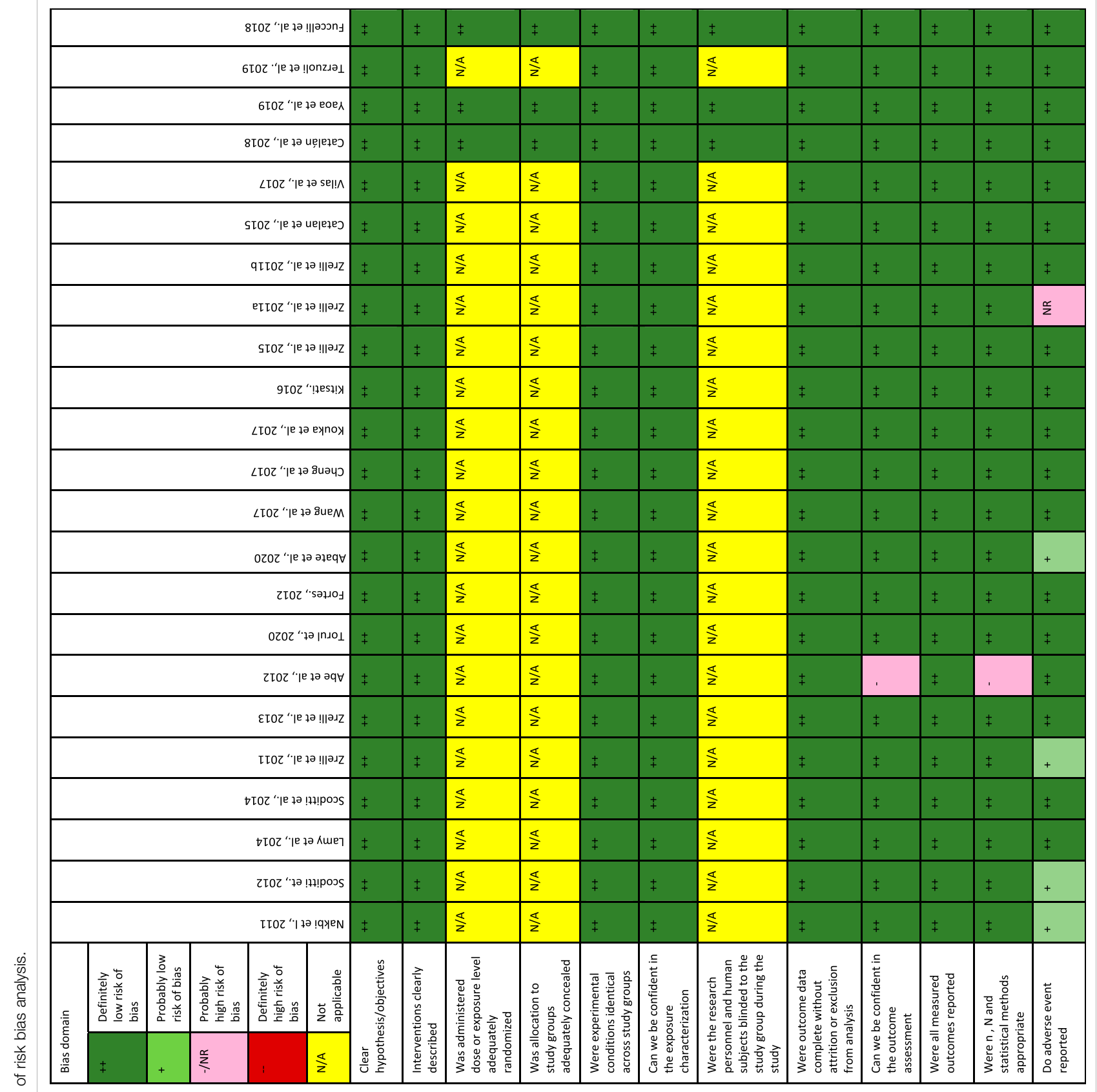


a scientific prove are both exciting and beneficial in future medical treatment. The association of plant derived antioxidants, specifically Hydroxytyrosol (HT) with lower risk factor and mortality in cardiovascular disease patients that consume olives products are well recognized. HT were found to exerted cardioprotective and anti-atherosclerotic effects in a randomized, double-blinded, placebo-controlled, crossover trial that were performed for 20 weeks (Quirós-Fernández et al., 2019). However, until now HT has not been investigated in attenuating intimal hyperplasia (IH) which if found beneficial could change the treatment of CVD patients significantly.

Therefore, we compile studies that utilize HT in vascular remodeling and critically review the mechanism that were elucidated. Endothelial functioning and healing are a crucial point in preventing further progression of $\mathrm{IH}$, as endothelial injury triggers migration of SMCs. HT antioxidant property provides an oxidative stress defense friendly environment that prevents endothelial dysfunction and apoptosis. This is facilitated by the activation of AMPK-FOXO3 (Zrelli et al., 2011b). The molecular action of HT downregulates NFKB pathway which improves NO production. HT also promote cellular survival from ROS induction (Torul et al., 2020). These series of evidence, allow us to proposed HT that could promote reendothelization in the site of endothelial injury.

Migration of smooth muscle cell (SMCs) is the direct causal effect following EC disruption in IH. Overall, direct effect of HT on SMCs were inhibition of proliferation and migration. HT inhibited SMCs migration and proliferation via blocking cell cycle regulated by ERK1/2 phosphorylation (Abate et al., 2012). Zrelli proved that NO production and Akt dephosphorylation could prevent VSMCs proliferation. He also reported these events triggered by activation of $\mathrm{PP} 2 \mathrm{~A}$ that leads to cell apoptosis (Zrelli et al., 2011a). Correspondingly, HT directly effect MMP 9 and MMP 2 reduction which indirectly inhibits migration of SMCs (Nakbi et al., 2011; Scoditti et al., 2012; Fortes et al., 2012; Scoditti et al., 2014).

With regards to dosage, up to $160 \mu \mathrm{M}$, HT promotes endothelial proliferation and functioning endothelium. HT efficiently reduced SMCs proliferation at a dosage of $100 \mu \mathrm{M}$. These findings strongly support our theory for the use HT as treatment for intimal hyperplasia where with further research, a perfect dosage that enables HT enhance reendothelization while inhibits SMCs migration. Therefore, we hope this evidence compilation will encourage researchers to investigate the use of HT in ex vivo intimal hyperplasia organ culture models in future.

\section{REFERENCES}

Abate, M., Pisanti, S., Caputo, M., Citro, M., Vecchione, C., and Martinelli, R. (2020). 3-Hydroxytyrosol Promotes Angiogenesis In Vitro by Stimulating Endothelial Cell Migration. Int. J. Mol. Sci. 21 (10), 3657. doi:10.3390/ ijms21103657

Abe, R., Beckett, J., Abe, R., Nixon, A., Rochier, A., Yamashita, N., et al. (2012). Olive Oil Polyphenols Differentially Inhibit Smooth Muscle Cell Proliferation through a G1/S Cell Cycle Block Regulated by ERK1/2. Int. J. Angiol. 21 (2), 069-076. doi:10.1055/s-0032-1315630

\section{CONCLUSION}

This systematic review collect evidences on molecular action of $\mathrm{HT}$ in the attenuation of $\mathrm{IH}$ in both in vitro and in vivo models. Supporting study on HT activity at the molecular level is presented in Tables $\mathbf{1}$ and $\mathbf{2}$ and further simplified in Figure 2. These consolidated findings uncovered the underlying pathways influenced by HT in IH suppression. HT promotes reendothelization by activating cell regulation pathways including AMPK/FOXO3, PI3K/AKT/mTOR and supressing VSMCs migration by disrupting cell cycle via inactivation of ERK1/2 and AKT. These findings can be further be applied in the treatment of IH by delivery of HT in future translational studies.

\section{DATA AVAILABILITY STATEMENT}

The original contributions presented in the study are included in the article/Supplementary Material, further inquiries can be directed to the corresponding author.

\section{AUTHOR CONTRIBUTIONS}

NS, MY, RI, and MR designed the research topic and questions of the systematic review. UV, NS, MY, and RI designed the study. UV, NS, and MY performed article selection and screening. UV, and NS carried out data collection, extraction, manuscript writing and data analysis. MY, RI, and MR performed final proofread of the manuscript.

\section{FUNDING}

This research is fully funded under the Fundamental Research Grant Scheme (FRGS) FRGS/1/2019/SKK08/UKM/03/3 by the Ministry of Education Malaysia. The funder does not have any contribution and decision on publishing or preparation of the manuscript.

\section{ACKNOWLEDGMENTS}

All the authors would like to thank the Faculty of Medicine, UKM, for the resources use to complete this review.

Adawiyah Razali, R., Lokanathan, Y., Yazid, M. D., Ansari, A. S., Bin Saim, A., and Bt Hj Idrus, R. (2019). Modulation of Epithelial to Mesenchymal Transition Signaling Pathways by Olea Europaea and its Active Compounds. Int. J. Mol. Sci. 20 (14), 3492. doi:10.3390/ijms20143492

Aguilar-Cazares, D., Chavez-Dominguez, R., Carlos-Reyes, A., Lopez-Camarillo, C., Hernadez de la Cruz, O. N., and Lopez-Gonzalez, J. S. (2019). Contribution of Angiogenesis to Inflammation and Cancer. Front. Oncol. 9, 1399. doi:10. 3389/fonc.2019.01399

Alfonso, F., and García-Guimaraes, M. (2017). Restenosis of Coronary Bioresorbable Vascular Scaffolds. Revista Española de Cardiología (English Edition) 70 (7), 527-531. doi:10.1016/j.rec.2017.02.024 
Anderson, J. L., Halperin, J. L., Albert, N. M., Bozkurt, B., Brindis, R. G., Curtis, L. H., et al. (2013). Management of Patients with Peripheral Artery Disease (Compilation of 2005 and 2011 ACCF/AHA Guideline Recommendations). Circulation 127 (13), 1425-1443. doi:10.1161/cir.0b013e31828b82aa

Barnard, N. D., Goldman, D. M., Loomis, J. F., Kahleova, H., Levin, S. M., Neabore, S., et al. (2019). Plant-based Diets for Cardiovascular Safety and Performance in Endurance Sports. Nutrients 11 (1), 1-10. doi:10.3390/nu11010130

Basatemur, G. L., Jørgensen, H. F., Clarke, M. C. H., Bennett, M. R., and Mallat, Z. (2019). Vascular Smooth Muscle Cells in Atherosclerosis. Nat. Rev. Cardiol. 16 (12), 727-744. doi:10.1038/s41569-019-0227-9

Belo, V. A., Guimarães, D. A., and Castro, M. M. (2015). Matrix Metalloproteinase 2 as a Potential Mediator of Vascular Smooth Muscle Cell Migration and Chronic Vascular Remodeling in Hypertension. J. Vasc. Res. 52 (4), 221-231. doi:10.1159/000441621

Braun, D., Baquet, M., Massberg, S., Mehilli, J., and Hausleiter, J. (2016). Collapse of a Bioresorbable Novolimus-Eluting Coronary Scaffold. JACC: Cardiovasc. Interventions 9 (1), e13-e14. doi:10.1016/j.jcin.2015.10.019

Burja, B., Kuret, T., Janko, T., Topalović, D., Živković, L., Mrak-Poljšak, K., et al. (2019). Olive Leaf Extract Attenuates Inflammatory Activation and DNA Damage in Human Arterial Endothelial Cells. Front. Cardiovasc. Med. 6, 56. doi:10.3389/fcvm.2019.00056

Camenzind, E., Steg, P. G., and Wijns, W. (2007). Response to Camenzind et al: Commentary. Circulation 115 (11), 1455. doi:10.1161/circulationaha.106. 666800

Catalán, Ú., López de las Hazas, M.-C., Piñol, C., Rubió, L., Motilva, M.-J., Fernandez-Castillejo, S., et al. (2018). Hydroxytyrosol and its Main Plasma Circulating Metabolites Attenuate the Initial Steps of Atherosclerosis through Inhibition of the MAPK Pathway. J. Funct. Foods 40, 280-291. doi:10.1016/j.jff. 2017.11.007

Catalán, Ú., López de las Hazas, M.-C., Rubió, L., Fernández-Castillejo, S., Pedret, A., de la Torre, R., et al. (2015). Protective Effect of Hydroxytyrosol and its Predominant Plasmatic Human Metabolites against Endothelial Dysfunction in Human Aortic Endothelial Cells. Mol. Nutr. Food Res. 59 (12), 2523-2536. doi:10.1002/mnfr.201500361

Chen, D., Tao, X., Wang, Y., Tian, F., Wei, Y., Chen, G., et al. (2015). Curcumin Accelerates Reendothelialization and Ameliorates Intimal Hyperplasia in Balloon-Injured Rat Carotid Artery via the Upregulation of Endothelial Cell Autophagy. Int. J. Mol. Med. 36 (6), 1563-1571. doi:10.3892/ijmm.2015.2365

Cheng, Y., Qu, Z., Fu, X., Jiang, Q., and Fei, J. (2017). Hydroxytyrosol Contributes to Cell Proliferation and Inhibits Apoptosis in Pulsed Electromagnetic Fields Treated Human Umbilical Vein Endothelial Cells In Vitro. Mol. Med. Rep. 16 (6), 8826-8832. doi:10.3892/mmr.2017.7701

Chin, K. Y., and Pang, K. L. (2017). Therapeutic Effects of Olive and its Derivatives on Osteoarthritis: From Bench to Bedside. Nutrients 9 (10), 1-18. doi:10.3390/ nu9101060

Costa, F., Vranckx, P., Leonardi, S., Moscarella, E., Ando, G., Calabro, P., et al. (2015). Impact of Clinical Presentation on Ischaemic and Bleeding Outcomes in Patients Receiving 6- or 24-month Duration of Dual-Antiplatelet Therapy after Stent Implantation: a Pre-specified Analysis from the PRODIGY (Prolonging Dual-Antiplatelet Treatment after Grading Stent-Induced Intimal Hyperplasia) Trial. Eur. Heart J. 36 (20), 1242-1251. doi:10.1093/eurheartj/ehv038

D’Angelo, C., Goldeck, D., Pawelec, G., Gaspari, L., Di Iorio, A., and Paganelli, R. (2020). Exploratory Study on Immune Phenotypes in Alzheimer's Disease and Vascular Dementia. Eur. J. Neurol. 27 (10), 1887-1894. doi:10.1111/ene.14360

Davies, M. G., and Hagen, P.-0. (1989). Pathobiology of Intimal Hyperplasia. $B r$. J. Surg., 81(9), 1254-1269. doi:10.1002/bjs.1800810904

De Roos, B., Zhang, X., Rodriguez Gutierrez, G., Wood, S., Rucklidge, G. J., Reid, M. D., et al. (2011). Anti-platelet Effects of Olive Oil Extract: In vitro Functional and Proteomic Studies. Eur. J. Nutr. 50 (7), 553-562. doi:10.1007/s00394-010-0162-3

de Vries, M. R., and Quax, P. H. A. (2018). Inflammation in Vein Graft Disease. Front. Cardiovasc. Med. 5, 1-13. doi:10.3389/fcvm.2018.00003

Fortes, C., García-Vilas, J. A., Quesada, A. R., and Medina, M. Á. (2012). Evaluation of the Anti-angiogenic Potential of Hydroxytyrosol and Tyrosol, Two BioActive Phenolic Compounds of Extra Virgin Olive Oil, in Endothelial Cell Cultures. Food Chem. 134 (1), 134-140. doi:10.1016/j.foodchem.2012.02.079

Fuccelli, R., Fabiani, R., and Rosignoli, P. (2018). Hydroxytyrosol exerts antiinflammatory and anti-oxidant activities in a mouse model of systemic inflammation. Molecules 23 (12). doi:10.3390/molecules 23123212
García-Vilas, J. A., Quesada, A. R., and Medina, M. Á. (2017). Hydroxytyrosol Targets Extracellular Matrix Remodeling by Endothelial Cells and Inhibits Both Ex Vivo and In Vivo Angiogenesis. Food Chem. 221, 1741-1746. doi:10.1016/j. foodchem.2016.10.111

Garg, U. C., and Hassid, A. (1989). Nitric Oxide-Generating Vasodilators and 8Bromo-Cyclic Guanosine Monophosphate Inhibit Mitogenesis and Proliferation of Cultured Rat Vascular Smooth Muscle Cells. J. Clin. Invest. 83 (5), 1774-1777. doi:10.1172/jci114081

Gellman, J., Ezekowitz, M. D., Sarembock, I. J., Azrin, M. A., Nochomowitz, L. E., Lerner, E., et al. (1991). Effect of Lovastatin on Intimal Hyperplasia after Balloon Angioplasty: A Study in an Atherosclerotic Hypercholesterolemic Rabbit. J. Am. Coll. Cardiol. 17 (1), 251-259. doi:10.1016/0735-1097(91) 90735-r

Gonzalo, N., Gonzalo, N., and Macaya, C. (2012). Absorbable Stent: Focus on Clinical Applications and Benefits. Vhrm 8 (1), 125-132. doi:10.2147/vhrm. s22551

Granados-Principal, S., Quiles, J. L., Ramirez-Tortosa, C. L., Sanchez-Rovira, P., and Ramirez-Tortosa, M. C. (2010). Hydroxytyrosol: From Laboratory Investigations to Future Clinical Trials. Nutr. Rev. 68 (4), 191-206. doi:10. 1111/j.1753-4887.2010.00278.x

Greer, E. L., Oskoui, P. R., Banko, M. R., Maniar, J. M., Gygi, M. P., Gygi, S. P., et al. (2007). The Energy Sensor AMP-Activated Protein Kinase Directly Regulates the Mammalian FOXO3 Transcription Factor. J. Biol. Chem. 282 (41), 30107-30119. doi:10.1074/jbc.m705325200

Guasch-ferré, M., Merino, J., Sun, Q., Fitó, M., Salas-salvadó, J., Fern, D., et al. (2019). Supplementation in a Physically Active Population. Sports Med. - Open 20 (1), 1-17. doi:10.3390/ijms20184567

Hamilos, M., Petousis, S., and Parthenakis, F. (2018). Interaction between Platelets and Endothelium: From Pathophysiology to New Therapeutic Options. Cardiovasc. Diagn. Ther. 8 (5), 568-580. doi:10.21037/cdt.2018.07.01

Hernáez, Á., Castañer, O., Elosua, R., Pintó, X., Estruch, R., Salas-Salvadó, J., et al. (2017). Mediterranean Diet Improves High-Density Lipoprotein Function in High-Cardiovascular-Risk Individuals. Circulation 135 (7), 633-643. doi:10. 1161/circulationaha.116.023712

Hillis, L. D., Smith, P. K., Anderson, J. L., Bittl, J. A., Bridges, C. R., Byrne, J. G., et al. (2012). 2011 ACCF/AHA guideline for coronary artery bypass graft surgery: executive summary: a report of the American College of Cardiology Foundation/American Heart Association Task Force on Practice Guidelines. J. Thorac. Cardiovasc. Surg. 143 (1), 4-34. doi:10.1016/j.jtcvs.2011.10.015

Hou, X., Song, J., Li, X.-N., Zhang, L., Wang, X., Chen, L., et al. (2010). Metformin Reduces Intracellular Reactive Oxygen Species Levels by Upregulating Expression of the Antioxidant Thioredoxin via the AMPK-FOXO3 Pathway. Biochem. Biophysical Res. Commun. 396 (2), 199-205. doi:10.1016/j.bbrc.2010.04.017

Huang, B., Dreyer, T., Heidt, M., Yu, J. C. M., Philipp, M., Hehrlein, F. W., et al. (2002). Insulin and Local Growth Factor PDGF Induce Intimal Hyperplasia in Bypass Graft Culture Models of Saphenous Vein and Internal Mammary Artery. Eur. J. CardioThoracic Surg. 21 (6), 1002-1008. doi:10.1016/s1010-7940(02)00111-2

Jennette, J. C., and Stone, J. R. (2014). "Diseases of Medium-Sized and Small Vessels," in Cellular and Molecular Pathobiology of Cardiovascular Disease, 197-219. doi:10.1016/B978-0-12-405206-2.00011-9

Jinnouchi, H., Torii, S., Sakamoto, A., Kolodgie, F. D., Virmani, R., and Finn, A. V. (2019). Fully Bioresorbable Vascular Scaffolds: Lessons Learned and Future Directions. Nat. Rev. Cardiol. 16 (5), 286-304. doi:10.1038/s41569018-0124-7

Joner, M., Nakazawa, G., Finn, A. V., Quee, S. C., Coleman, L., and Acampado, E. (2018). Endothelial cell recovery between comparator polymer-based drugeluting stents. J. Am. Coll. Cardiol. 52 (5), 333-342. doi:10.1016/j.jacc.2008. 04.030

Kamann, S., Haase, T., Stolzenburg, N., Löchel, M., Peters, D., and Schnorr, J. (2019). Resveratrol- Coated Balloon Catheters in Porcine Coronary and Peripheral Arteries. Int. J. Mol. Sci. 20 (9), 2285. doi:10.3390/ijms20092285

Kamil, K., Yazid, M. D., Idrus, R. B. H., and Kumar, J. (2020). Hydroxytyrosol Promotes Proliferation of Human Schwann Cells: An In Vitro Study. Int. J. Environ. Res. Public Health 17 (12), 1-11. doi:10.3390/ijerph17124404

Karaarslan, K., Abud, B., Albayrak, G., Aykut, K., Ergür, B. U., and Silistreli, E. (2015). The Effect of Resveratrol on Intimal Hyperplasia and Endothelial Proliferation of Rabbit Carotid Artery Anastomosis. Interactive Cardiovasc. Thorac. Surg. 20 (1), 15-20. doi:10.1093/icvts/ivu316 
Khandelwal, A. R., Hebert, V. Y., Kleinedler, J. J., Rogers, L. K., Ullevig, S. L., Asmis, R., et al. (2012). Resveratrol and Quercetin Interact to Inhibit Neointimal Hyperplasia in Mice with a Carotid Injury. J. Nutr. 142 (8), 1487-1494. doi:10. 3945/jn.112.162628

Kim, H., Caulfield, L. E., Garcia-Larsen, V., Steffen, L. M., Coresh, J., and Rebholz, C. M. (2019). Plant-Based Diets Are Associated with a Lower Risk of Incident Cardiovascular Disease, Cardiovascular Disease Mortality, and All-Cause Mortality in a General Population of Middle- Aged Adults. J. Am. Heart Assoc. 8 (16), e012865. doi:10.1161/jaha.119.012865

Kim, N., Hwangbo, C., Lee, S., and Lee, J.-H. (2013). Eupatolide Inhibits PDGFInduced Proliferation and Migration of Aortic Smooth Muscle Cells through ROS-dependent Heme Oxygenase-1 Induction. Phytother. Res. 27 (11), 1700-1707. doi:10.1002/ptr.4924

Kitsati, N., Mantzaris, M. D., and Galaris, D. (2016). Hydroxytyrosol Inhibits Hydrogen Peroxide-Induced Apoptotic Signaling via Labile Iron Chelation. Redox Biol. 10 , 233-242. doi:10.1016/j.redox.2016.10.006

Koniari, I., Mavrilas, D., Apostolakis, E., Papadimitriou, E., Papadaki, H., Papalois, A., et al. (2016). Inhibition of Atherosclerosis Progression, Intimal Hyperplasia, and Oxidative Stress by Simvastatin and Ivabradine May Reduce Thoracic Aorta's Stiffness in Hypercholesterolemic Rabbits. J. Cardiovasc. Pharmacol. Ther. 21 (4), 412-422. doi:10.1177/1074248415617289

Kotronoulas, A., Pizarro, N., Serra, A., Robledo, P., Joglar, J., Rubió, L., et al. (2013). Dose-dependent Metabolic Disposition of Hydroxytyrosol and Formation of Mercapturates in Rats. Pharmacol. Res. 77, 47-56. doi:10.1016/j.phrs.2013. 09.001

Kouka, P., Priftis, A., Stagos, D., Angelis, A., Stathopoulos, P., Xinos, N., et al. (2017). Assessment of the Antioxidant Activity of an Olive Oil Total Polyphenolic Fraction and Hydroxytyrosol from a Greek Olea Europea Variety in Endothelial Cells and Myoblasts. Int. J. Mol. Med. 40 (3), 703-712. doi:10.3892/ijmm.2017.3078

Lamy, S., Ouanouki, A., Béliveau, R., and Desrosiers, R. R. (2014). Olive Oil Compounds Inhibit Vascular Endothelial Growth Factor Receptor-2 Phosphorylation. Exp. Cel Res. 322 (1), 89-98. doi:10.1016/j.yexcr.2013.11.022

Lee, D. H., and Hernandez, J. M. d. la. T. (2018). The Newest Generation of DrugEluting Stents and beyond. Eur. Cardiol. Rev. 13 (1), 54-59. doi:10.15420/ecr. 2018:8:2

Li, Q., Wu, X., Liu, Y., Zhang, M., Bai, X., and Chen, C. (2017). The Effect of Anagliptin on Intimal Hyperplasia of Rat Carotid Artery after Balloon Injury. Mol. Med. Rep. 16 (6), 8003-8010. doi:10.3892/mmr.2017.7667

Li, X. N., Song, J., Zhang, L., LeMaire, S. A., Hou, X., Zhang, C., et al. (2009). Activation of the AMPK-FOXO3 Pathway Reduces Fatty Acid-Induced Increase in Intracellular Reactive Oxygen Species by Upregulating Thioredoxin. Diabetes 58 (10), 2246-2257. doi:10.2337/db08-1512

Lindqvist, A., Nilsson, B. O., Ekblad, E., and Hellstrand, P. (2001). Plateletderived Growth Factor Receptors Expressed in Response to Injury of Differentiated Vascular Smooth Muscle In Vitro: Effects on $\mathrm{Ca} 2+$ and Growth Signals. Acta Physiol. Scand. 173 (2), 175-184. doi:10.1046/j.1365201x.2001.00873.x

Liu, D., Huang, Y., Bu, D., Liu, A. D., Holmberg, L., Jia, Y., et al. (2014). Sulfur Dioxide Inhibits Vascular Smooth Muscle Cell Proliferation via Suppressing the Erk/MAP Kinase Pathway Mediated by cAMP/PKA Signaling. Cel Death Dis. 5. doi:10.1038/cddis.2014.229

Loscalzo, J., and Jin, R. C. (2010). Vascular Nitric Oxide: Formation and Function. J. Blood Med. 2010 (1), 147-162. doi:10.2147/JBM.S7000

Luo, Q., Liu, X., Li, Z., Huang, C., Zhang, W., Meng, J., et al. (2014). Degradation Model of Bioabsorbable Cardiovascular Stents. PLoS ONE 9 (11), 1-9. doi:10. 1371/journal.pone. 0110278

Man, R. C., Sulaiman, N., Ishak, M. F., Idrus, R. B. H., Rahman, M. R. A., and Yazid, M. D. (2020). The Effects of Pro-inflammatory and Anti-inflammatory Agents for the Suppression of Intimal Hyperplasia: An Evidence-Based Review. Int. J. Environ. Res. Public Health 17 (21), 1-22. doi:10.3390/ijerph17217825

Marcantoni, E., Di Francesco, L., Dovizio, M., Bruno, A., and Patrignani, P. (2012). Novel Insights into the Vasoprotective Role of Heme Oxygenase-1. Int. J. Hypertens. 2012, 127910. doi:10.1155/2012/127910

Martinon, F. (2010). Signaling by ROS Drives Inflammasome Activation. Eur. J. Immunol. 40 (3), 616-619. doi:10.1002/eji.200940168

Michel, J. B., Li, Z., and Lacolley, P. (2012). Smooth Muscle Cells and Vascular Diseases. Cardiovasc. Res. 95 (2), 135-137. doi:10.1093/cvr/cvs172
Mylonaki, I., Allain, E., Strano, F., Allémann, E., Corpataux, J. M., Meda, P., et al. (2018). Evaluating Intimal Hyperplasia under Clinical Conditions. Interactive Cardiovasc. Thorac. Surg. 27 (3), 427-436. doi:10.1093/icvts/ivy101

Nakbi, A., Dabbou, S., Champion, S., Fouchier, F., Mehri, S., Attia, N., et al. (2011). Modulation of the Superoxide Anion Production and MMP-9 Expression in PMA Stimulated THP-1 Cells by Olive Oil Minor Components: Tyrosol and Hydroxytyrosol. Food Res. Int. 44 (2), 575-581. doi:10.1016/j.foodres.2010. 12.010

Napolitano, A., De Lucia, M., Panzella, L., and d'Ischia, M. (2010). "The Chemistry of Tyrosol and Hydroxytyrosol: Implications for Oxidative Stress," in Olives and Olive Oil in Health and Disease Prevention, 1225-1232. doi:10.1016/B9780-12-374420-3.00134-0

Nedeljkovic, Z. S., Gokce, N., and Loscalzo, J. (2003). Mechanisms of Oxidative Stress and Vascular Dysfunction. Postgrad. Med. J. 79 (930), 195-200. doi:10. 1136/pmj.79.930.195

Nemzer, B. V., Yashin, A. Y., Vedenin, A. N., Yashin, Y. I., Yashunsky, D. V., Nifantiev, N. E., et al. (2019). Selected Powerful Natural Antioxidants: Structure, Food Sources, Antioxidant Activities, and Important Health Benefits. J. Food Res. 8 (1), 60. doi:10.5539/jfr.v8n1p60

Ng, S. F., Tan, L. S., and Buang, F. (2017). Transdermal Anti-inflammatory Activity of Bilayer Film Containing Olive Compound Hydroxytyrosol: Physical Assessment, In Vivo Dermal Safety and Efficacy Study in Freund's Adjuvant-Induced Arthritic Rat Model. Drug Dev. Ind. Pharm. 43 (1), 108-119. doi:10.1080/03639045.2016.1224893

Norton, K. A., and Popel, A. S. (2016). Effects of Endothelial Cell Proliferation and Migration Rates in a Computational Model of Sprouting Angiogenesis. Scientific Rep. 6, 1-10. doi:10.1038/srep36992

Olmos, Y., Valle, I., Borniquel, S., Tierrez, A., Soria, E., Lamas, S., et al. (2009). Mutual Dependence of Foxo3a and PGC-1a in the Induction of Oxidative Stress Genes. J. Biol. Chem. 284 (21), 14476-14484. doi:10.1074/jbc. m807397200

Pamukcu, B., Lip, G. Y. H., and Shantsila, E. (2011). The Nuclear Factor - Kappa B Pathway in Atherosclerosis: A Potential Therapeutic Target for Atherothrombotic Vascular Disease. Thromb. Res. 128 (2), 117-123. doi:10. 1016/j.thromres.2011.03.025

Pi, Y., Zhang, L. L., Li, B. H., Guo, L., Cao, X. J., Gao, C. Y., et al. (2013). Inhibition of Reactive Oxygen Species Generation Attenuates TLR4-Mediated Proinflammatory and Proliferative Phenotype of Vascular Smooth Muscle Cells. Lab. Invest. 93 (8), 880-887. doi:10.1038/labinvest.2013.79

Pober, J. S., and Sessa, W. C. (2007). Evolving Functions of Endothelial Cells in Inflammation. Nat. Rev. Immunol. 7 (10), 803-815. doi:10.1038/nri2171

Quirós-Fernández, R., López-Plaza, B., Bermejo, L. M., Palma-Milla, S., and Gómez-Candela, C. (2019). Supplementation with Hydroxytyrosol and Punicalagin Improves Early Atherosclerosis Markers Involved in the Asymptomatic Phase of Atherosclerosis in the Adult Population: A Randomized, Placebo-Controlled, Crossover Trial. Nutrients 11 (3), 1-16. doi:10.3390/nu11030640

Raffetto, J. D., and Khalil, R. A. (2008). Matrix Metalloproteinases and Their Inhibitors in Vascular Remodeling and Vascular Disease. Biochem. Pharmacol. 75 (2), 347-359. doi:10.1016/j.bcp.2007.07.004

Regazzoli, D., Leone, P. P., Colombo, A., and Latib, A. (2017). New Generation Bioresorbable Scaffold Technologies: An Update on Novel Devices and Clinical Results. J. Thorac. Dis. 9 (Suppl. 9), S979-S985. doi:10.21037/jtd.2017.07.104

Reglero-Real, N., Colom, B., Bodkin, J. V., and Nourshargh, S. (2016). Endothelial Cell Junctional Adhesion Molecules. Arteriosclerosis, Thromb. Vasc. Biol. 36 (10), 2048-2057. doi:10.1161/atvbaha.116.307610

Rodríguez-Morató, J., Boronat, A., Kotronoulas, A., Pujadas, M., Pastor, A., Olesti, E., et al. (2016). Metabolic Disposition and Biological Significance of Simple Phenols of Dietary Origin: Hydroxytyrosol and Tyrosol. Drug Metab. Rev. 48 (2), 218-236. doi:10.1080/03602532.2016.1179754

Romagnolo, D. F., and Selmin, O. I. (2017). Mediterranean Diet and Prevention of Chronic Diseases. Nutr. Today 52 (5), 208-222. doi:10.1097/nt. 0000000000000228

Rubió, L., Farràs, M., de La Torre, R., Macià, A., Romero, M. P., Valls, R. M., et al. (2014). Metabolite Profiling of Olive Oil and Thyme Phenols after a Sustained Intake of Two Phenol-Enriched Olive Oils by Humans: Identification of Compliance Markers. Food Res. Int. 65 59-68. doi:10.1016/j.foodres.2014. 05.009 
Sandoo, A., Veldhuijzen van Zanten, J. J. C. ., Metsios, G. S., Carroll, D., and Kitas, G. D. (2010). The Endothelium and its Role in Regulating Vascular Tone. Open Cardiovasc. Med. J. 4 (1), 302-312. doi:10.2174/1874192401004010302

Scoditti, E., Calabriso, N., Massaro, M., Pellegrino, M., Storelli, C., Martines, G., et al. (2012). Mediterranean Diet Polyphenols Reduce Inflammatory Angiogenesis through MMP-9 and COX-2 Inhibition in Human Vascular Endothelial Cells: A Potentially Protective Mechanism in Atherosclerotic Vascular Disease and Cancer. Arch. Biochem. Biophys. 527 (2), 81-89. doi:10.1016/j.abb.2012.05.003

Scoditti, E., Nestola, A., Massaro, M., Calabriso, N., Storelli, C., De Caterina, R., et al. (2014). Hydroxytyrosol Suppresses MMP-9 and COX-2 Activity and Expression in Activated Human Monocytes via PKCa and PKC $\beta 1$ Inhibition. Atherosclerosis 232 (1), 17-24. doi:10.1016/j.atherosclerosis.2013.10.017

Soler-Cantero, A., Jové, M., Cacabelos, D., Boada, J., Naudí, A., Romero, M. P., et al. (2012). Plant-Derived Phenolics Inhibit the Accrual of Structurally Characterised Protein and Lipid Oxidative Modifications. PLoS ONE 7 (8), e43308. doi:10.1371/journal.pone.0043308

Stettler, C., Wandel, S., Allemann, S., Kastrati, A., Morice, M. C., Schömig, A., et al. (2007). Outcomes Associated with Drug-Eluting and Bare-Metal Stents: a Collaborative Network Meta- Analysis. Lancet 370 (9591), 937-948. doi:10. 1016/s0140-6736(07)61444-5

Stone, G. W., Moses, J. W., Ellis, S. G., Schofer, J., Dawkins, K. D., Morice, M.-C., et al. (2007). Safety and Efficacy of Sirolimus- and Paclitaxel-Eluting Coronary Stents. New Engl. J. Med. 356 (10), 998-1008. doi:10.1056/nejmoa067193

Storniolo, C. E., Sacanella, I., Mitjavila, M. T., Lamuela-Raventos, R. M., and Moreno, J. J. (2019). Bioactive Compounds of Cooked Tomato Sauce Modulate Oxidative Stress and Arachidonic Acid Cascade Induced by Oxidized LDL in Macrophage Cultures. Nutrients 11 (8), 1880. doi:10.3390/nu11081880

Sun, L., Zhao, R., Zhang, L., Zhang, T., Xin, W., Lan, X., et al. (2012). Salvianolic acid A inhibits PDGF-BB induced vascular smooth muscle cell migration and proliferation while does not constrain endothelial cell proliferation and nitric oxide biosynthesis. Molecules. 17 (3), 3333-3347.

Tagliafierro, L., Officioso, A., Sorbo, S., Basile, A., and Manna, C. (2015). The Protective Role of Olive Oil Hydroxytyrosol against Oxidative Alterations Induced by Mercury in Human Erythrocytes. Food Chem. Toxicol. 82, 59-63. doi:10.1016/j.fct.2015.04.029

Tejada, S., Pinya, S., Mar Bibiloni, M. del., Tur, J. A., Pons, A., and Sureda, A. (2016). Cardioprotective Effects of the Polyphenol Hydroxytyrosol from Olive Oil. Curr. Drug Targets 18 (13), 1477-1486. doi:10.2174/1389450117666161005150650

Terzuoli, E., Nannelli, G., Giachetti, A., Morbidelli, L., Ziche, M., and Donnini, S. (2020). Targeting endothelial-to-mesenchymal transition: the protective role of hydroxytyrosol sulfate metabolite. Eur. J. Nutrit. 59. doi:10.1007/s00394-01901920-x

Thompson, A. M., Martin, K. A., and Rzucidlo, E. M. (2014). Resveratrol Induces Vascular Smooth Muscle Cell Differentiation through Stimulation of SirT1 and AMPK. PLoS ONE 9 (1), 1-10. doi:10.1371/journal.pone.0085495

Tolva, V., Mazzola, S., Zerbi, P., Casana, R., Albertini, M., Calvillo, L., et al. (2016). A Successful Experimental Model for Intimal Hyperplasia Prevention Using a Resveratrol- Delivering Balloon. J. Vasc. Surg. 63 (3), 788-794. doi:10.1016/j.jvs. 2014.09.035

Torul, H., Küçükboyaci, N., Tamer, U., and Karasu, Ç. (2020). Evaluation of Phenolic Compounds and Protective Effects of Olive (Olea Europaea L.) Leaf Extracts on Endothelial Cells against Hydrogen Peroxide-Induced Toxicity. J. Res. Pharm. 24 (4), 497-507. doi:10.35333/jrp.2020.198

Tousoulis, D., Kampoli, A.-M., Tentolouris Nikolaos Papageorgiou, C., and Stefanadis, C. (2011). The Role of Nitric Oxide on Endothelial Function. Curr. Vasc. Pharmacol. 10 (1), 4-18. doi:10.2174/157016112798829760

Tuso, P., Stoll, S. R., and William, W. Li. (2015). "A Plant-Based Diet, Atherogenesis, and Coronary Artery Disease Prevention," in Ethnicity, 19, 62-67. doi:10.7812/TPP/14-0361

Urban, P., Mehran, R., Colleran, R., Angiolillo, D. J., Byrne, R. A., Capodanno, D., et al. (2019). Defining High Bleeding Risk in Patients Undergoing Percutaneous Coronary Intervention. Circulation 140 (3), 240-261. doi:10.1161/ circulationaha.119.040167

Vilaplana-Pérez, C., Auñón, D., García-Flores, L. A., and Gil-Izquierdo, A. (2014). Hydroxytyrosol and Potential Uses in Cardiovascular Diseases, Cancer, and AIDS. Front. Nutr. 1, 1-11. doi:10.3389/fnut.2014.00018
Wadey, K., Lopes, J., Bendeck, M., and George, S. (2018). Role of Smooth Muscle Cells in Coronary Artery Bypass Grafting Failure. Cardiovasc. Res. 114 (4), 601-610. doi:10.1093/cvr/cry021

Wang, W., Jing, T., Yang, X., He, Y., Wang, B., Xiao, Y., et al. (2018). Hydroxytyrosol Regulates the Autophagy of Vascular Adventitial Fibroblasts through the SIRT1-Mediated Signaling Pathway. Can. J. Physiol. Pharmacol. 96, 88-96. doi:10.1139/cjpp-2016-0676

Wei, X., Fang, Z., Sheng, J., Wang, Y., and Lu, P. (2020). Honokiol-mesoporous Silica Nanoparticles Inhibit Vascular Restenosis via the Suppression of TGF- $\beta$ Signaling Pathway. Int. J. Nanomedicine 15, 5239-5252. doi:10.2147/ijn. s250911

Widmer, R. J., Flammer, A. J., Lerman, L. O., and Lerman, A. (2015). The Mediterranean diet, its components, and cardiovascular disease. Am. J. Med. 128 (3), 229-238. doi:10.1016/j.amjmed.2014.10.014

Xu, K., Al-Ani, M. K., Pan, X., Chi, Q., Dong, N., and Qiu, X. (2018). Plant-derived Products for Treatment of Vascular Intima Hyperplasia Selectively Inhibit Vascular Smooth Muscle Cell Functions. Evidence-Based Complement. Altern. Med. 2018, 3549312. doi:10.1155/2018/3549312

Yang, X., Li, Y., Li, Y., Ren, X., Zhang, X., Hu, D., et al. (2017). Oxidative StressMediated Atherosclerosis: Mechanisms and Therapies. Front. Physiol. 8, 1-16. doi:10.3389/fphys.2017.00600

Yao, F., Yang, G., Xian, Y., Wang, G., Zheng, Z., Jin, Z., et al. (2019). The Protective Effect of Hydroxytyrosol Acetate against Inflammation of Vascular Endothelial Cells Partly through the SIRT6-Mediated PKM2 Signaling Pathway. Food Funct. 10 (9), 5789-5803. doi:10.1039/c9fo00586b

Yurdagul, A., Kleinedler, J. J., McInnis, M. C., Khandelwal, A. R., Spence, A. L., Orr, A. W., et al. (2014). Resveratrol Promotes Endothelial Cell Wound Healing under Laminar Shear Stress through an Estrogen Receptor- $\alpha$-dependent Pathway. Am. J. Physiol. - Heart Circulatory Physiol. 306 (6), 797-806. doi:10.1152/ajpheart.00892.2013

Zhan, Y., Kim, S., Izumi, Y., Izumiya, Y., Nakao, T., Miyazaki, H., et al. (2003). Role of JNK, P38, and ERK in Platelet-Derived Growth Factor-Induced Vascular Proliferation, Migration, and Gene Expression. Arteriosclerosis, Thromb. Vasc. Biol. 23 (5), 795-801. doi:10.1161/01.ATV.0000066132.32063.F2

Zhao, Y., Vanhoutte, P. M., and Leung, S. W. S. (2015). Vascular Nitric Oxide: Beyond eNOS. J. Pharmacol. Sci. 129 (2), 83-94. doi:10.1016/j.jphs.2015. 09.002

Zrelli, H., Kusunoki, M., and Miyazaki, H. (2015). Role of Hydroxytyrosoldependent Regulation of HO-1 Expression in Promoting Wound Healing of Vascular Endothelial Cells via Nrf2 De Novo Synthesis and Stabilization. Phytotherapy Res. 29 (7), 1011-1018. doi:10.1002/ptr.5339

Zrelli, H., Matsuka, M., Araki, M., Zarrouk, M., and Miyazaki, H. (2011a). Hydroxytyrosol Induces Vascular Smooth Muscle Cells Apoptosis through No Production and PP2A Activation with Subsequent Inactivation of Akt. Planta Med. 77 (15), 1680-1686. doi:10.1055/s-0030-1271073

Zrelli, H., Matsuoka, M., Kitazaki, S., Zarrouk, M., and Miyazaki, H. (2011b). Hydroxytyrosol Reduces Intracellular Reactive Oxygen Species Levels in Vascular Endothelial Cells by Upregulating Catalase Expression through the AMPK-FOXO3a Pathway. Eur. J. Pharmacol. 660 (2-3), 275-282. doi:10.1016/ j.ejphar.2011.03.045

Zrelli, H., Wei Wu, C., Zghonda, N., Shimizu, H., and Miyazaki, H. (2013). Combined Treatment of Hydroxytyrosol with Carbon Monoxide-Releasing Molecule-2 Prevents TNF a -induced Vascular Endothelial Cell Dysfunction through No Production with Subsequent NF B Inactivation. Biomed. Res. Int. 2013, 912431. doi:10.1155/2013/912431

Conflict of Interest: The authors declare that the research was conducted in the absence of any commercial or financial relationships that could be construed as a potential conflict of interest.

Copyright (๑) 2021 Vijakumaran, Yazid, Hj Idrus, Abdul Rahman and Sulaiman. This is an open-access article distributed under the terms of the Creative Commons Attribution License (CC BY). The use, distribution or reproduction in other forums is permitted, provided the original author(s) and the copyright owner(s) are credited and that the original publication in this journal is cited, in accordance with accepted academic practice. No use, distribution or reproduction is permitted which does not comply with these terms. 